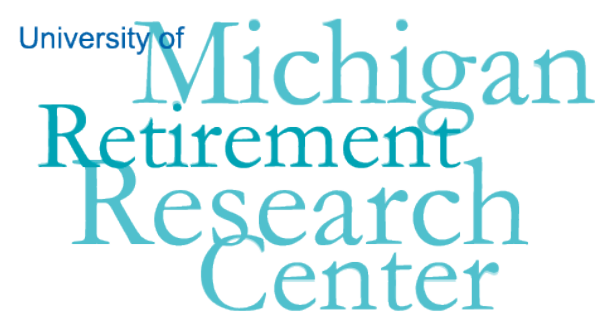

Working Paper

WP 2013-295

\title{
Labor Force Transitions at Older Ages: The Roles of Work Environment and Personality
}

\author{
Marco Angrisani, Michael D. Hurd, Erik Meijer, \\ Andrew M. Parker, and Susann Rohwedder
}

\begin{tabular}{|l|l|}
\hline $\mathrm{M}$ & $\mathrm{R}$ \\
\hline $\mathrm{R}$ & $\mathrm{C}$ \\
\hline
\end{tabular}

Project \#: UM13-Q5 



\title{
Labor Force Transitions at Older Ages: The Roles of Work Environment and Personality
}

\author{
Marco Angrisani \\ University of Southern California and RAND Corporation \\ Michael D. Hurd \\ RAND Corporation \\ Erik Meijer \\ University of Southern California and RAND Corporation
}

Andrew M. Parker

RAND Corporation

Susann Rohwedder

RAND Corporation

September 2013

\author{
Michigan Retirement Research Center \\ University of Michigan \\ P.O. Box 1248 \\ Ann Arbor, MI 48104 \\ www.mrrc.isr.umich.edu \\ (734) 615-0422
}

\section{Acknowledgements}

This work was supported by a grant from the Social Security Administration through the Michigan Retirement Research Center (Grant \# 5 RRC08098401-05-00). The findings and conclusions expressed are solely those of the author and do not represent the views of the Social Security Administration, any agency of the Federal government, or the Michigan Retirement Research Center. 


\title{
Labor Force Transitions at Older Ages: The Roles of Work Environment and Personality
}

\begin{abstract}
Besides compensation and financial incentives, several other work-related factors may affect individual retirement decisions. Specifically, job characteristics such as autonomy, skill variety, task significance and difficulty, stress and physical demands, peer pressure and relations with coworkers, play a crucial role in determining psychological commitment to work at older ages. While financial preparedness for retirement and health shocks are often cited as main predictors of the choice to exit the labor force, there exists relatively little research documenting the extent to which the work environment itself and its interaction with economic variables influence retirement decisions. We document that job characteristics are associated with labor force transitions at older ages, in particular transitions to retirement and part-time employment. Additionally, we show that while personality traits do not directly drive labor force transitions, the effect of job characteristics on labor supply outcomes varies with the "intensity" of personality traits. We also document that job characteristics themselves are strongly related to personality traits. This suggests that, depending on their personality, individuals may select into specific jobs, whose characteristics ultimately shape their retirement paths.
\end{abstract}

\section{Citation}

Angrisani, Marco, Michael D. Hurd, Erik Meijer, Andrew M. Parker, and Susann Rohwedder (2013). "Labor Force Transitions at Older Ages: The Roles of Work Environment and Personality.” Ann Arbor MI: University of Michigan Retirement Research Center (MRRC) Working Paper, WP 2013-295.

http://www.mrrc.isr.umich.edu/publications/papers/pdf/wp295.pdf

\section{Authors’ Acknowledgements}

This research was supported by the Social Security Administration through the Michigan Retirement Research Center (MRRC), project UM13-Q5. We thank Leandro Carvalho and Hans van Kippersluis for discussions that led to improvements in the paper and Orla Hayden for data construction. The corresponding author is marco.angrisani@usc.edu. 


\section{Introduction}

What shapes retirement paths for different individuals has not been completely unfolded yet. The timing of retirement has been found to be strongly influenced by the incentives embedded in the rules determining Social Security provisions and employer-provided pension benefits (see Hurd, 1990 and Lumsdaine and Mitchell, 1999 for reviews), and by the availability of early retirement options (Gruber and Wise, 1999 and 2004). Other "push" factors are labor market rigidities (Hurd et al., 2008; Garcia Perez and Sanchez-Martin, 2008), poor health (Currie and Madrian, 1999) and family care-giving obligations (Crespo, 2006; Fevang et al., 2008).

While financial preparedness for retirement and health shocks are often cited as main predictors of the choice to exit the labor force, there exists relatively little research documenting the extent to which the work environment itself and its interaction with economic variables influence retirement decisions. Unfavorable work conditions may adversely impact one's motivation and willingness to pursue goals on their career job. This may induce some to seek out alternative employment (bridge or part-time jobs) and others to withdraw from the labor force altogether. Whether one or the other option prevails hinges crucially on individuals' financial needs and proclivity to work, on the availability of jobs for older workers, as well as on the perception that individuals have about job opportunities at older ages. Conceivably, all these factors are linked to and affected by specific personality traits.

The goal of this study is twofold. First, we aim to assess the extent to which job characteristics lead fulltime employees to move to part-time employment, retirement, or out of the labor force. Second, we wish to investigate the relationship between labor supply decisions and personality traits at old ages and examine whether individuals with different personalities cope differently with similar work environments and exhibit different retirement paths.

Intuitively, job characteristics, work conditions and ability to adapt to them should predict retirement proclivity. For example, high levels of work-related stress may induce individuals to retire earlier. Adequate financial rewards and generous benefits are likely to keep individuals on the job, but they might also lead to anticipated exits from the labor force, should they boost wealth accumulation to finance retirement. The interactions among work environment, job satisfaction, and labor supply decisions are rather complex. Such complexity is further increased by the potential for both endogeneity and heterogeneity in these relations. First, individual preferences shaping labor supply decisions may also be responsible for self-selection into specific jobs or occupations. Second, aspects that may encourage some to retire may prevent others from doing so: what is stimulating or challenging for some individuals may be demanding for others. We hypothesize that selection into certain jobs and heterogeneity in labor force transitions can be partly explained by personality traits. We study these issues for a longitudinal sample of older individuals interviewed in the Health and Retirement Study.

The paper proceeds as follows. In section 2, we review some findings from the literature on job characteristics and retirement. In section 3, we discuss the relation between personality and economic outcomes, and what the potential implications of this are for labor force transitions at older ages. In section 4, we describe the data used in the empirical analysis. Section 5 presents the econometric specification of the models that we adopt to study labor force transitions, while section 6 provides the results of this investigation. Section 7 studies the relation between job characteristics and job satisfaction on the one hand and personality traits on the other hand. This allows us to refine the interpretation of the 
models for labor force transitions and gain further insights into the potential pathways through which personality affects labor market outcomes. Section 8 concludes.

\section{Job characteristics and retirement}

The decision to retire involves weighting the utility of leisure against the (dis)utility of working. From this point of view, one would expect workers to retire earlier, the more unpleasant, difficult, and stressful their jobs are. The timing of retirement, however, is critically determined by an individual's financial needs. Despite undesirable job conditions, some may be forced to remain employed full-time or, depending on the degree of job flexibility, move to part-time before they are financially prepared to retire. Other factors beyond financial preparedness may also play an important role. In the United States, for instance, the strong link between employment and health insurance, coupled with the significant rise in medical expenditures, may prevent workers from fully retiring until they qualify for Medicare.

The economic literature has mainly focused on how compensation, pension arrangements and other financial incentives shape labor supply decisions at older ages (Gruber and Wise, 2004), while there exists relatively little evidence about the extent to which the work environment itself and non-monetary job characteristics affect retirement decisions. The few existing studies have produced mixed results.

Bartel (1982) finds that unfavorable working conditions are not significant predictors of the retirement probability of older workers. Filer and Petri (1988) show that physical demands and stress reduce retirement age, while the possibility of part-time employment increases it. Hayward et al. (1989) document that job complexity delays the exit from the labor force, as opposed to physical requirements which hasten it. Hurd and McGarry (1993) find only a weak association between self-reported job demands and subjective probabilities of working to ages 62 and 65. More recently, Blekesaune and Solem (2005) suggest that disability retirement is related to physical job strains and that low autonomy in job tasks is associated with early retirement.

Most of these contributions use occupational-level codes to identify job requirement and, as a consequence, may not capture heterogeneity within job classes or in the perception that individuals have about their work environments. Hurd and McGarry (1993) use self-reports about job characteristics but focus on the intention to retire rather than on actual transitions into retirement. Blekesaune and Solem (2005) consider only a few dimensions of job requirements, namely physical strains, stress and level of autonomy.

In this paper we use a rich microeconomic dataset and individual self-reports to examine the effects of a wide range of job characteristics and perceived job conditions on observed changes in labor force status. Specifically, we look at transitions from full-time employment to part-time employment, retirement, and being unemployed or out of the labor force. Our analysis covers a variety of dimensions including, but not limited to, job financial incentives and health insurance benefits, physical and mental effort, degree of flexibility in hours of work, level of task difficulty and work-related stress, age discrimination in the workplace, and quality of the relationship with coworkers and supervisors. 


\section{Personality and economic outcomes}

Almlund et al. (2011) give an overview of personality psychology and its relation to economic outcomes. They emphasize the Big Five personality traits, which the field recognizes as the main dimensions of personality, and provide empirical evidence that personality traits are related to economic outcomes. Personality offers predictive value in addition to measures of cognitive ability such as IQ, which have a long and strong track record of predictive power for economic outcomes. Table 1.3 in Almlund et al. (2011), which is adapted from John and Srivastava (1999), gives a brief description of the Big Five personality traits and a list of "facets" that are contained in them. These descriptions generate some tentative hypotheses about how they might be related to the labor market outcomes we are studying here.

- Openness to experience may be related to higher likelihood of retirement if retirement is seen as a new experience, but a lower likelihood if the work environment frequently generates new experiences. Thus, there may be a main effect as well as an interaction with job characteristics.

- Conscientiousness is associated with delay of gratification, ambition, and work ethic, and thus may be associated with later retirement. However, it is also related with better preparation for retirement (see below), which has the opposite effect.

- A facet of extraversion is excitement seeking or being adventurous, but also being sociable. These may again be associated with both earlier and later retirement, depending on whether the work environment provides these kinds of stimulation.

- Agreeableness includes the modesty and "not demanding" facets, the association of which with retirement may again depend on job characteristics.

- Neuroticism or emotional stability is associated with worrying, depression, and vulnerability to stress, as well as impulsiveness. This appears to point at earlier retirement, unless the individual is not well prepared for retirement as a result of these characteristics.

It is generally found that conscientiousness is the personality trait most strongly related to economic outcomes. Specifically, Hurd et al. (2012) find that it is associated with better preparation for retirement, whereas neuroticism is associated with worse preparation for retirement. This is in line with the finding of Duckworth et al. (2012) that conscientious individuals have higher lifetime earnings and more wealth conditional upon earnings. Thus, conscientious individuals may retire earlier because they are less financially constrained. On the other hand, conscientiousness is also positively related to academic achievement (Poropat, 2009) and job performance (Roberts, Kuncel, Shiner, Caspi, \& Goldberg, 2007), and this may have the opposite effect of staying longer in the workforce because of a preference for work over leisure and higher productivity.

The Big Five personality traits are relatively stable over the lifecycle. Specht et al. (2011) show that there are some general trends with age and that personality traits respond to certain major life events, such as entering the labor force and retiring. However, the magnitude of these changes is rather small. Lucas and Donnellan (2011) find similar patterns. Cobb-Clark and Schurer (2012) largely replicate these results and conclude that while personality traits are not completely constant, changes are small, unrelated to other variables of interest, and not economically meaningful. These studies also document that changes in personality are most likely to occur very early (before age 40) or very late (after age 70) in life. 


\section{Data}

We use data from the Health and Retirement Study (HRS), a multipurpose, longitudinal household survey representing the U.S. population over the age of 50. Since 1992, the HRS has surveyed ageeligible respondents and their spouses every two years to track transitions from work into retirement, to measure economic well-being in later life and to monitor changes in health status as individuals age. Initially, the HRS consisted of individuals born 1931-1941 and their spouses, but additional cohorts have been added in 1993, 1998, 2004, and 2010. As of 2010, the number of individuals ever interviewed by the HRS is 36,986. These individuals are members of 23,375 sampled households, or new spouses of members of these households.

We primarily use data from the RAND version of the HRS, version M (Chien et al., 2013). The RAND HRS is a large user-friendly subset of the HRS that combines data from all waves, adds information that may have been provided by the spouse to the respondent's record, has consistent imputation of financial variables, and consistent definition and naming of variables. To this, we add additional variables from the employment module of each wave obtained from the RAND FAT files. These are partially preprocessed files with all the raw HRS data of each wave combined into a single respondent-level file.

In 2004, the HRS piloted a supplemental self-administered questionnaire that was left with the respondent after the completion of an in-person core interview. Because of its specific administration mode, this is called the Leave-Behind (LB) Questionnaire. It asks about respondents' evaluations of their life circumstances, subjective well-being, and lifestyle. We will especially rely on two sets of questions measuring personality traits and work-related beliefs ranging from work satisfaction to work/personal life balance. Since 2004, the LB questionnaire has been administered in each biennial wave to a (randomly selected) rotating $50 \%$ of the core sample who were assigned to an in-person interview. As of 2010, about 15,000 respondents have completed the LB questionnaire. The rotating design implies that, for each participant, measures are available every other wave (or every four years).

We will use data over the period 2002-2010. Since our focus is on labor market outcomes of individuals on the verge of retirement, we restrict our analysis to full-time employed respondents between 51 and 79 years of age. This leaves us with a sample of 9,541 individuals and 20,436 observations.

\subsection{Core questionnaire}

The HRS core questionnaire provides us with information about individual demographics, labor force status, financial situation, and health status. We assign respondents to different labor force status groups according to their employment situation. In doing so, we combine the RAND HRS definition of labor force status with information about whether the individual is self-employed, the number of working hours per week and the number of weeks worked in a year on the main job. Specifically, we classify individuals as full-time employees if they are not self-employed, and work at least 35 hours per week and 36 weeks per year on their main job. We follow Maestas (2010) and classify individuals as part-time employees if they are not self-employed, and work either less than 35 hours per week or less than 36 weeks per year on their main job. We classify individuals as retired if they are defined as such according to the RAND HRS labor force status. We form a final group consisting of those who are either out of the labor force or unemployed according to the RAND HRS labor force status. We exclude from our analysis individuals who report being disabled or self-employed. This leaves us with a sample of 8,064 individuals and 16,925 observations. 
We focus on those in full-time employment in a certain wave and consider transitions to the four possible categories of labor force status (as described above) in the next wave. There are 4,816 workers with valid transitions for a total of 10,723 observations. Table 1 shows the prevalence of these transitions in our sample, aggregated across all the waves we consider.

The majority of the full-time employed are still employed full-time in the subsequent wave, although this percentage is of course much larger for individuals age 51-61 than individuals age 62-79. Only about half of the changes are from full-time employed to retired, while more than a third concern individuals who move to part-time, especially among relatively older workers and female workers. Transitions from full-time employment to out of the labor force or unemployment are less frequent, although somewhat more common for those below the age of 62 and for female workers.

Table 1: Labor force status transitions from full-time employment

\begin{tabular}{lrrrrrrrrrr}
\hline Next wave & \multicolumn{1}{c}{ All } & \multicolumn{1}{c}{ Age 51-61 } & \multicolumn{2}{c}{ Age 62-79 } & \multicolumn{2}{c}{ Males } & \multicolumn{2}{c}{ Females } \\
\cline { 2 - 11 } labor force status & $\mathrm{N}$ & $\%$ & $\mathrm{~N}$ & $\%$ & $\mathrm{~N}$ & $\%$ & $\mathrm{~N}$ & $\%$ & $\mathrm{~N}$ & $\%$ \\
\hline Full-time employee & 8,015 & 74.8 & 6,232 & 80.8 & 1,783 & 59.2 & 3,921 & 76.0 & 4,094 & 73.6 \\
Part-time employee & 909 & 8.5 & 509 & 6.6 & 400 & 13.3 & 353 & 6.8 & 556 & 10.0 \\
Retired & 1,371 & 12.8 & 643 & 8.3 & 728 & 24.2 & 694 & 13.5 & 677 & 12.2 \\
Out of LF/Unemployed & 428 & 4.0 & 329 & 4.3 & 99 & 3.3 & 193 & 3.7 & 235 & 4.2 \\
\hline Total & 10,723 & 100.0 & 7,713 & 100.0 & 3,010 & 100.0 & 5,161 & 100.0 & 3,010 & 100.0 \\
\hline
\end{tabular}

The HRS core questionnaire asks respondents who are currently working for pay about several aspects of their jobs. These include information about employer-provided health insurance, hourly wage, physical and mental requirements, degree of job flexibility, incentives and pressure to retire, and level of work-related stress. In section 5, we study to what extent these job conditions influence employment transitions. The appendix provides further details about how these questionnaire items are combined into indexes describing specific job characteristics.

\subsection{Leave-behind questionnaire}

As mentioned above, the HRS leave-behind (LB) questionnaire elicits respondents' evaluations of job characteristics. The goal of these questions is to tap into the perceived ability to work with respect to a job’s physical and mental demands and interference with personal life. They also capture multiple facets of job satisfaction, measure different work stressors, and convey information about how individuals relate to and cope with their working environment. Thus, the LB questionnaire offers a subjective assessment of job conditions that complements the relatively more objective measures available in the core interview. We use the LB questionnaire to study the relationship between individuals' perception of working life and their subsequent employment transitions. Since the LB questionnaire is given to half of the core HRS sample with a rotational design, the sample size for this analysis is smaller than the one using only measures from the core questionnaire. Further details are given in the appendix. 
The LB questionnaire also provides measures of personality. Specifically, respondents are asked to use a 4-point scale (where 1 corresponds to "not at all" and 4 corresponds to "a lot") to rate themselves on a series of adjectives associated with the Big Five personality traits: openness to experience, conscientiousness, extraversion, agreeableness, and neuroticism (emotional stability). Following the procedure described in the appendix, we transform individual self-ratings into five indexes corresponding to the Big Five personality traits. We also consider answers to two other separate items where individuals are asked to rate themselves as "hardworking" and "active". Because of the rotational design of the LB questionnaire, we can only measure personality every other wave and, since personality was not measured in 2004, we only have one observation for most of the respondents. In order to maximize the sample size for our analysis, we assume that personality traits are stable over time and assign to each individual the average of their available personality measures over the observation period. Our assumption receives support from recent studies demonstrating that Big Five personality traits are relatively stable for working-age adults (Cobb-Clark and Schurer, 2012) and that stability peaks between the ages of 60 and 70 (Lucas and Donnellan, 2011), a range covering 70\% of our sample.

\section{Econometric specification}

We estimate multinomial choice models for the four possible employment transitions described above, where the determinants of employment outcomes are individual demographics, job characteristics, personality traits, and the interaction between job characteristics and personality traits. Formally, we are interested in the probability that a full-time employee transits to a different employment status in the next wave, given certain demographics, job characteristics and personality traits:

$$
P_{i j}=\operatorname{Pr}\left(Y_{i}=j \mid X_{i}, \mathrm{JobC}_{i}, \text { PTraits }_{i}\right)=F_{j}\left(X_{i}, \mathrm{JobC}_{i}, \text { PTraits }_{i}, \theta\right),
$$

where $Y_{i}$ is the labor force status in the next wave, $j=1$ (full-time), 2 (part-time), 3 (retired), or 4 (out of the labor force or unemployed), $X_{i}$ are individual demographics, $\mathrm{JobC}_{i}$ are job characteristics, and PTraits $_{i}$ are personality traits. The function $F_{j}$ is a probability function depending on a vector of unknown parameters $\theta$.

We adopt the common multinomial logit model, and hence our most comprehensive specification is:

where

$$
F_{j}\left(X_{i}, \operatorname{JobC}_{i}, \operatorname{PTraits}_{i}, \theta\right)=\frac{\exp \left(V_{i j}\right)}{\sum_{k=1}^{4} \exp \left(V_{i k}\right)}, \quad j=1, \ldots, 4
$$

$$
V_{i j}=X_{i}^{\prime} \alpha_{j}+\operatorname{JobC}_{i}^{\prime} \beta_{j}+\operatorname{PTraits}_{i}^{\prime} \gamma_{j}+\left(\mathrm{JobC}_{i} \times \text { PTraits }_{i}\right)^{\prime} \delta_{j}
$$

and $\theta$ is a vector that collects all the parameters in the model.

We start with specifications including only individual demographics and job characteristics and then move to specifications including individual demographics and personality traits. Finally, we estimate the most comprehensive model described here where we allow employment transitions to be functions of individual demographics, job characteristics, personality traits, and interactions of job characteristics and personality traits. 
Since we are interested in assessing the effect of job characteristics and personality traits on the probability that a certain employment transition takes place, we focus on the marginal effects only. For each individual $i$ and explanatory variable $Z$, these are defined as:

$$
\mathrm{ME}_{i j z}=\frac{\partial F_{j}\left(X_{i}, \mathrm{JobC}_{i}, \text { PTraits }_{i}, \theta\right)}{\partial Z_{i}} .
$$

In section 4, we report estimates of the average marginal effects, that is, estimates of the average of the individual marginal effects:

$$
\overline{\mathrm{ME}}_{j z}=\frac{1}{N} \sum_{i=1}^{N} \mathrm{ME}_{i j z}
$$

Note that what we for simplicity call an individual $i$ in these formulas is actually an observation of a respondent in a certain wave, and we may have multiple observations (from different waves) for each respondent. Standard errors are computed by the delta method and clustered at the respondent level to account for repeated employment transitions for the same respondent.

\section{Regression results for employment transitions}

\subsection{Employment transitions and individual demographics}

Before focusing on job characteristics and personality traits, it is useful to first look at how basic demographics are related to employment transitions. This will help us understand the relative importance of job characteristics or personality traits in driving labor force transitions. Table 2 shows the estimated marginal effects for the baseline set of controls that will also be present in all other regressions. This set includes an indicator for being female, age, indicators for being age 62 or older (the earliest age to start receiving Social Security retirement benefits) and age 65 or older (the full Social Security retirement age for much of the sample and age of Medicare eligibility), education, marital status, spouse's working status, an indicator for fair or poor self-reported health status ("poor health”), total household wealth, total household income, and time effects.

Some interesting patterns emerge. Female workers are less likely to remain in full-time employment and more likely to move to a part-time job. As individuals age, they tend to either move to part-time or to retire altogether. Full-time employees over the age of 65 are more likely to remain in full-time employment and less-likely to retire. A possible explanation for this finding is that these workers have a taste for work or may hold better jobs. As a consequence, their retirement decisions are driven to a lesser extent by crossing the Social Security full retirement age and by Medicare eligibility. We also observe an education gradient, with more educated workers more likely to stay in full-time employment and less likely to be either unemployed or out of the labor force.

Poor health decreases the probability of remaining in full-time employment by 7 percentage points. It increases the probability of retirement and being out of the labor force or unemployed by 6 and 2 percentage points, respectively. A higher level of household wealth is associated with a higher chance of retiring, whereas a higher level of household income makes full-time employees less likely to move to part-time or out of the labor force. The effect of the recent financial crisis is visible in the coefficients of 
the wave dummies: the likelihood of remaining in full-time employment between 2008 and 2010 is almost 6 percentage points lower than between 2002 and 2004, while the likelihood of being either unemployed or out of the labor force is about 5 percentage points higher. There is no evidence of such a trend in earlier years, when workers were more likely to remain in full-time employment and less likely to transit into retirement.

Table 2: Marginal effects of the baseline covariates

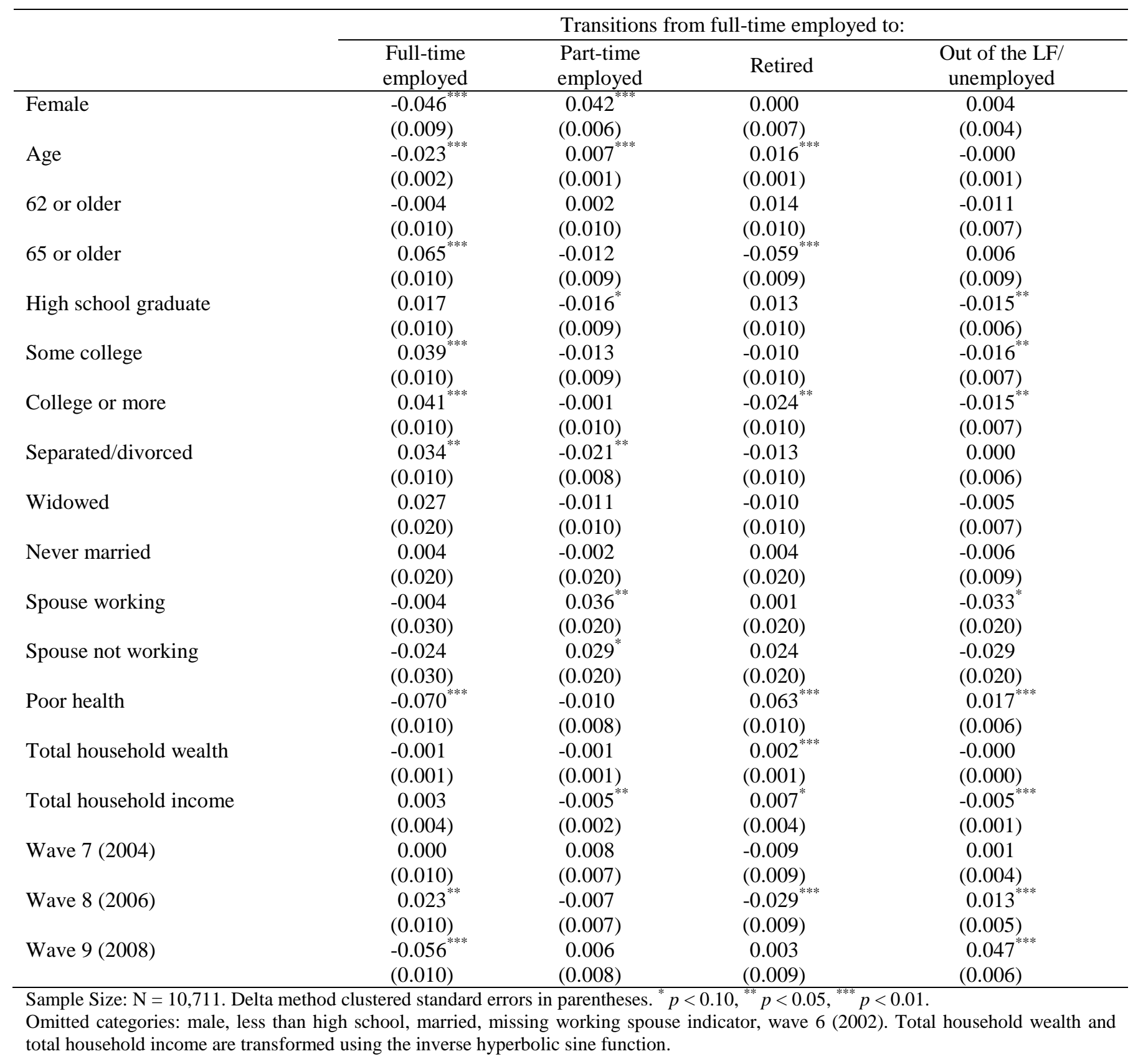




\subsection{Employment transitions and job characteristics}

We now turn to examine the effect of job characteristics on employment transitions, over and above the explanatory power of the individual demographics described in the previous section. Table 3 shows the marginal effects of job characteristics as elicited by the employment module of the HRS core questionnaire.

Table 3: Marginal effects of job characteristics from the core questionnaire

\begin{tabular}{|c|c|c|c|c|}
\hline & \multicolumn{4}{|c|}{ Transitions from full-time employed to: } \\
\hline & $\begin{array}{l}\text { Full-time } \\
\text { employed }\end{array}$ & $\begin{array}{l}\text { Part-time } \\
\text { employed }\end{array}$ & Retired & $\begin{array}{c}\text { Out of the LF/ } \\
\text { unemployed }\end{array}$ \\
\hline \multicolumn{5}{|l|}{ Panel A: Health Benefits and Pay } \\
\hline R Covered by Employer Health Ins. & $\begin{array}{l}0.064^{\text {*** }} \\
(0.010)\end{array}$ & $\begin{array}{l}-0.049^{* * *} \\
(0.008)\end{array}$ & $\begin{array}{l}-0.006 \\
(0.009)\end{array}$ & $\begin{array}{l}-0.010^{* *} \\
(0.005)\end{array}$ \\
\hline Spouse Covered by R's Employer Health Ins. & $\begin{array}{c}0.014 \\
(0.010)\end{array}$ & $\begin{array}{l}-0.008 \\
(0.007)\end{array}$ & $\begin{array}{l}0.006 \\
(0.008)\end{array}$ & $\begin{array}{l}-0.012^{* * *} \\
(0.005)\end{array}$ \\
\hline R Covered by Spouse’s Employer Health Ins. & $\begin{array}{l}-0.069 * * * \\
(0.010)\end{array}$ & $\begin{array}{l}0.043^{* * *} \\
(0.010)\end{array}$ & $\begin{array}{l}0.023^{* *} \\
(0.010)\end{array}$ & $\begin{array}{c}0.003 \\
(0.007)\end{array}$ \\
\hline (Log) Hourly Wage & $\begin{array}{c}0.022^{* *} \\
(0.009) \\
\end{array}$ & $\begin{array}{l}-0.031^{* * *} \\
(0.006)\end{array}$ & $\begin{array}{l}0.024^{* * *} \\
(0.007)\end{array}$ & $\begin{array}{l}-0.015^{* * *} \\
(0.004)\end{array}$ \\
\hline \multicolumn{5}{|l|}{ Panel B: Job Requirements } \\
\hline Job Requires Physical Effort & $\begin{array}{l}-0.018 * * * \\
(0.005)\end{array}$ & $\begin{array}{l}0.010^{* * *} \\
(0.003)\end{array}$ & $\begin{array}{l}0.008^{* *} \\
(0.004)\end{array}$ & $\begin{array}{l}-0.001 \\
(0.002)\end{array}$ \\
\hline Job Requires Good Eyesight & $\begin{array}{l}-0.012 * * \\
(0.006)\end{array}$ & $\begin{array}{c}0.000 \\
(0.004)\end{array}$ & $\begin{array}{l}0.011^{* *} \\
(0.005)\end{array}$ & $\begin{array}{c}0.001 \\
(0.003)\end{array}$ \\
\hline Job Requires Intense Concentration & $\begin{array}{l}-0.000 \\
(0.006)\end{array}$ & $\begin{array}{l}-0.002 \\
(0.004)\end{array}$ & $\begin{array}{c}0.001 \\
(0.004)\end{array}$ & $\begin{array}{c}0.002 \\
(0.003)\end{array}$ \\
\hline Job Requires People Skills & $\begin{array}{c}0.004 \\
(0.006)\end{array}$ & $\begin{array}{c}0.008^{*} \\
(0.004)\end{array}$ & $\begin{array}{l}-0.005 \\
(0.004)\end{array}$ & $\begin{array}{l}-0.007 * * * \\
(0.003)\end{array}$ \\
\hline Job Require Use of Computer & $\begin{array}{l}0.016^{* * * *} \\
(0.004)\end{array}$ & $\begin{array}{l}-0.012^{* * *} \\
(0.003)\end{array}$ & $\begin{array}{l}-0.001 \\
(0.003)\end{array}$ & $\begin{array}{l}-0.002 \\
(0.002)\end{array}$ \\
\hline \multicolumn{5}{|l|}{ Panel C: Work Environment } \\
\hline Level of Difficulty/Stress & $\begin{array}{l}-0.012^{*} \\
(0.006)\end{array}$ & $\begin{array}{l}-0.004 \\
(0.004)\end{array}$ & $\begin{array}{l}0.019 * * * \\
(0.005)\end{array}$ & $\begin{array}{l}-0.004 \\
(0.003)\end{array}$ \\
\hline Age Discrimination & $\begin{array}{l}-0.025^{* * *} \\
(0.007) \\
\end{array}$ & $\begin{array}{l}-0.007 \\
(0.005)\end{array}$ & $\begin{array}{l}0.032^{* * *} \\
(0.005)\end{array}$ & $\begin{array}{l}-0.000 \\
(0.003)\end{array}$ \\
\hline \multicolumn{5}{|l|}{ Panel D: Job Flexibility } \\
\hline R Cannot Reduce Hours of Work & $\begin{array}{l}0.021^{* *} \\
(0.009)\end{array}$ & $\begin{array}{l}-0.051^{* * *} \\
(0.006)\end{array}$ & $\begin{array}{l}0.027^{* * *} \\
(0.007)\end{array}$ & $\begin{array}{c}0.003 \\
(0.004)\end{array}$ \\
\hline R Wants but Cannot Reduce Hours of Work & $\begin{array}{l}-0.065^{* * *} \\
(0.010)\end{array}$ & $\begin{array}{l}0.021^{* * *} \\
(0.008)\end{array}$ & $\begin{array}{l}0.042^{* * *} \\
(0.010)\end{array}$ & $\begin{array}{c}0.002 \\
(0.006)\end{array}$ \\
\hline Preference for/Possibility of Bridge Job & $\begin{array}{l}-0.003 \\
(0.009) \\
\end{array}$ & $\begin{array}{c}0.007 \\
(0.005) \\
\end{array}$ & $\begin{array}{l}-0.007 \\
(0.007)\end{array}$ & $\begin{array}{c}0.002 \\
(0.004) \\
\end{array}$ \\
\hline \multicolumn{5}{|l|}{ Panel E: Work Enjoyment } \\
\hline R Enjoys Going to Work & $\begin{array}{l}0.054^{* * *} \\
(0.007)\end{array}$ & $\begin{array}{l}-0.002 \\
(0.004)\end{array}$ & $\begin{array}{l}-0.045^{* * *} \\
(0.006)\end{array}$ & $\begin{array}{l}-0.008^{* *} \\
(0.004)\end{array}$ \\
\hline
\end{tabular}

Sample Size: $\mathrm{N}=10,711$. Delta Method clustered standard errors in parentheses. ${ }^{*} p<0.10,{ }^{* *} p<0.05,{ }^{* * *} p<0.01$.

Controls: all demographics as in Table 2.

Among the determinants of labor supply decisions at old ages, the availability of health care insurance may play a key role. The results in Panel A of Table 3 support this statement. When respondents are 
covered by an employer provided health insurance plan they are 6.5 percentage points more likely to remain in full-time employment, 5 percentage points less likely to move to part-time and 1 percentage point less likely to be out of the labor force or unemployed. Conversely, the likelihood that full-time employees transit into part-time or retirement altogether is higher for those covered by the spouse's health insurance. It should be noted that these effects are net of the impact of age and Medicare eligibility, which are both controlled for in the regressions. ${ }^{1}$

Besides health benefits, financial incentives are important drivers of employment transitions. Specifically, a higher hourly wage is associated with a higher probability of remaining in full-time employment and lower probability of moving to part-time or out of the labor force. Interestingly, those with a higher wage are also more likely to retire. This may reflect an income effect: keeping household total financial resources constant, those with a taste for leisure and a better paid job are in a better position to retire.

Panel B of Table 3 shows the estimated marginal effects of a series of job requirements. If the job demands a significant level of physical effort, then workers are less likely to remain in full-time employment and more likely to either switch to part-time or retire altogether. On the other hand, those for whom the use of computer is highly required tend to stay in full-time employment. These findings are not surprising since the former are plausibly blue collar employees, while the latter are more likely white collar employees.

We use two variables to describe the work environment (Panel $\mathrm{C}$ in Table 3). The first concerns the individuals' perceived difficulty and stress associated with their jobs. This is positive correlated with the probability of moving from full-time employment to retirement. The second is a combination of two items describing the extent to which older employees may be discriminated in the workplace. More precisely, HRS respondents are asked whether in decisions about promotion younger individuals are preferred to older ones and whether there is any pressure on older workers to retire before age 65. Answers are provided on a 1 to 4 scale, where 1 and 4 indicate strong disagreement and strong agreement with these statements, respectively. The estimated marginal effects reveal that a one-step increase on this scale is associated with a decrease in the likelihood of remaining in full-time employment of 2.5 percentage points and an increase in the likelihood of retirement of 3.2 percentage points.

The ability of varying hours of work per day or number of days per week may play a key role in influencing labor supply decisions of individuals approaching retirement. The HRS questionnaire features several questions about job flexibility. One asks "Could you reduce the number of hours in your regular work schedule?” We estimate that those who cannot are 2 and 3 percentage points more likely to remain in full-time and transit to retirement, respectively. On the other hand, they are 5 percentage points less likely to move to part-time. A follow-up question for those who cannot reduce their hours of work asks "Would you like to do so even if your earnings were reduced in the same proportion?" We find that answering "yes" to this question is associated with a 6.5 percentage point decrease in the probability of remaining in full-time employment and a 4.2 percentage point increase in the probability of retirement. Workers who want but cannot reduce hours of work are also 2 percentage points more likely to move to part-time. This result is plausibly driven by those who, being subject to this constraint, changed employer across two consecutive waves in order to switch to part-time (roughly $13 \%$ of our

\footnotetext{
${ }^{1}$ We obtain very similar results when we restrict the sample to employees below the age of 65 or below the age of 62 .
} 
sample). Two other questions ask whether individuals would like to reduce hours gradually as they age and whether their employer would let older workers move to a less demanding job. We combine the answers to these questions in one single index, which we call "Preference for/Possibility of Bridge Job". We find no evidence that this variable influences employment transitions. ${ }^{2}$

Panel E in Table 3 shows the effect of work enjoyment on labor supply decisions. HRS respondents are asked whether they enjoy going to work. Answers are elicited using a 4-point scale, where 1 corresponds to strong disagreement with the statement and 4 to strong agreement. Our estimates indicate that a onestep increase on this scale is associated with a 5.5 percentage point increase in the likelihood of remaining in full-time employment and a 4.5 and 1 percentage point decrease in likelihood of being retired and out of the labor force, respectively.

In Table 4, we perform a similar exercise as in Table 3 but rely on evaluations of job conditions as reported in the LB questionnaire. Because of the rotational design of the LB questionnaire, the sample size for this analysis is substantially reduced (from around 10,500 respondents in Table 3 to around 2,000 respondents in Table 4).

Table 4: Marginal effects of job characteristics from the leave-behind questionnaire

\begin{tabular}{|c|c|c|c|c|}
\hline & \multicolumn{4}{|c|}{ Transitions from full-time employed to: } \\
\hline & $\begin{array}{l}\text { Full-time } \\
\text { employed }\end{array}$ & $\begin{array}{l}\text { Part-time } \\
\text { employed }\end{array}$ & Retired & $\begin{array}{c}\text { Out of the LF/ } \\
\text { unemployed }\end{array}$ \\
\hline \multicolumn{5}{|c|}{ Panel A: Interaction between Work and Personal Life } \\
\hline Work Interferes with Personal Life & $\begin{array}{l}-0.034^{* *} \\
(0.010)\end{array}$ & $\begin{array}{c}0.002 \\
(0.009)\end{array}$ & $\begin{array}{l}0.024^{* *} \\
(0.010)\end{array}$ & $\begin{array}{c}0.008 \\
(0.007)\end{array}$ \\
\hline Personal Life Interferes with Work & $\begin{array}{l}-0.049^{* *} \\
(0.020)\end{array}$ & $\begin{array}{c}0.021^{*} \\
(0.013)\end{array}$ & $\begin{array}{c}0.022 \\
(0.015) \\
\end{array}$ & $\begin{array}{c}0.006 \\
(0.010)\end{array}$ \\
\hline \multicolumn{5}{|l|}{ Panel B: Incentives/Disincentives } \\
\hline Treated Unfairly at Work & $\begin{array}{l}-0.031^{* * *} \\
(0.009)\end{array}$ & $\begin{array}{c}0.009 \\
(0.006)\end{array}$ & $\begin{array}{c}0.009 \\
(0.007)\end{array}$ & $\begin{array}{l}0.013^{* * *} \\
(0.005)\end{array}$ \\
\hline Rewards and Recognition & $\begin{array}{l}0.026^{* *} \\
(0.010)\end{array}$ & $\begin{array}{l}-0.009 \\
(0.007)\end{array}$ & $\begin{array}{c}0.001 \\
(0.009)\end{array}$ & $\begin{array}{l}-0.018^{* * *} \\
(0.007)\end{array}$ \\
\hline Poor Job Prospects & $\begin{array}{l}-0.043^{* * *} \\
(0.010)\end{array}$ & $\begin{array}{c}0.007 \\
(0.008)\end{array}$ & $\begin{array}{c}0.008 \\
(0.010)\end{array}$ & $\begin{array}{l}0.026^{* * *} \\
(0.007)\end{array}$ \\
\hline A Lot to Say about What Happens at Work ${ }^{\dagger}$ & $\begin{array}{c}0.030^{*} \\
(0.020)\end{array}$ & $\begin{array}{l}-0.002 \\
(0.010)\end{array}$ & $\begin{array}{c}0.018 \\
(0.010)\end{array}$ & $\begin{array}{l}-0.046^{* * *} \\
(0.010)\end{array}$ \\
\hline Good Training Opportunities $^{\dagger}$ & $\begin{array}{c}0.041^{* *} \\
(0.020)\end{array}$ & $\begin{array}{l}-0.016 \\
(0.010)\end{array}$ & $\begin{array}{c}0.008 \\
(0.020)\end{array}$ & $\begin{array}{l}-0.033^{* * *} \\
(0.010)\end{array}$ \\
\hline \multicolumn{5}{|l|}{ Panel C: Work Environment } \\
\hline Good Relationship with Coworkers $^{\dagger}$ & $\begin{array}{l}0.058^{* *} \\
(0.020)\end{array}$ & $\begin{array}{l}-0.047^{* * *} \\
(0.020)\end{array}$ & $\begin{array}{c}0.018 \\
(0.020)\end{array}$ & $\begin{array}{l}-0.030^{* *} \\
(0.010)\end{array}$ \\
\hline 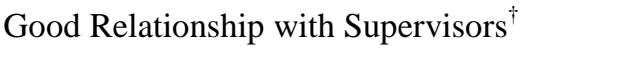 & $\begin{array}{l}0.057^{* * *} \\
(0.020)\end{array}$ & $\begin{array}{l}-0.032^{* * *} \\
(0.010)\end{array}$ & $\begin{array}{c}0.007 \\
(0.020)\end{array}$ & $\begin{array}{l}-0.033^{* * *} \\
(0.010)\end{array}$ \\
\hline \multicolumn{5}{|l|}{ Panel D: Job Satisfaction/Dissatisfaction } \\
\hline Job is Demanding & $\begin{array}{l}-0.041^{* *} \\
(0.020)\end{array}$ & $\begin{array}{c}0.005 \\
(0.010)\end{array}$ & $\begin{array}{c}0.004 \\
(0.010)\end{array}$ & $\begin{array}{c}0.032^{* * *} \\
(0.009)\end{array}$ \\
\hline Bothered or Upset on the Job & $\begin{array}{l}-0.022^{* *} \\
(0.010)\end{array}$ & $\begin{array}{c}0.004 \\
(0.007)\end{array}$ & $\begin{array}{c}0.006 \\
(0.008)\end{array}$ & $\begin{array}{c}0.011^{*} \\
(0.006)\end{array}$ \\
\hline Satisfied with the Job & $\begin{array}{c}0.036^{* * *} \\
(0.010)\end{array}$ & $\begin{array}{l}-0.011 \\
(0.007)\end{array}$ & $\begin{array}{l}-0.005 \\
(0.008)\end{array}$ & $\begin{array}{l}-0.020^{* * *} \\
(0.005)\end{array}$ \\
\hline
\end{tabular}

\footnotetext{
${ }^{2}$ We also run separate regressions for the two variables comprising the index and find no predictive power for both.
} 
Sample Size: $\mathrm{N}=2,072$. For job characteristics marked with $\dagger$ sample size is $\mathrm{N}=865$. Delta Method clustered standard errors in parentheses. ${ }^{*} p<0.10,{ }^{* *} p<0.05,{ }^{* * *} p<0.01$. Controls: all demographics as in Table 2.

Using a 4-point scale, where 1 means "rarely" and 4 "most of the time", respondents state the extent to which work and personal life interfere with each other. Individuals who perceive that their work prevents them from fulfilling their personal responsibilities are less likely to remain in full-time employment and more likely to retire. There is similar evidence for those whose family and personal life drain the energies they need for their job, although the effects are less precisely estimated in this case.

In Panel B of Table 4, we consider a wide range of incentives and disincentives to work. These include the incidence of unfair treatments, the existence of rewards and recognition for work, the lack of good job prospects, having control over what happens, and receiving good training to perform the job. The estimated marginal effects reveal a common pattern: the perceived lack of incentives makes individuals less likely to remain in full-time employment and more likely to be either unemployed or out of the labor force, but does not influence transitions to part-time or retirement. This suggests that those who miss incentives are also those who select into worst jobs and whose chances of being laid off are relatively higher.

We also look at how the work environment influences employment transitions via the relationship with coworkers and supervisors. HRS respondents are confronted with a 4-point scale and asked how much they agree with the following three statements about coworkers - (1) "my coworkers listen to me when I need to talk about work-related problems"; (2) "my coworkers help me with difficult tasks at work"; (3) "my coworkers help me in crisis situations at work" - and with the following four statements about supervisors - (1) "my supervisor is helpful to me in getting the job done"; (2) "my supervisor is willing to extend himself/herself to help me perform my job"; (3) "my supervisor takes pride in my accomplishments at work"; (4) "my supervisor tries to make my job as interesting as possible". We combine the answers to these questions into two single indexes and relate them to changes in employment status over consecutive waves. As far as a good relationship with coworkers is concerned, we find that a one-step increase on the 4-point "agreement scale" is associated with a 6 percentage increase in the likelihood of remaining in full-time employment, a 5 percentage point decrease in the likelihood of moving to part-time and a 3 percentage point decrease in the likelihood of being unemployed or out of the labor force. Having a good relationship with supervisors has an analogous impact on employment transitions.

Finally, Panel D in Table 4 shows the effects of three indicators of job satisfaction/dissatisfaction. Not surprisingly, those who are satisfied with their job are significantly more likely to stay in full-time employment. In contrast, those who think that their job is too demanding or feel bothered and upset when they are at work are less likely to remain full-time employees across consecutive waves.

\subsection{Employment transitions and personality traits}

In this section, we relate employment transitions to personality traits. For this purpose, we perform two separate regressions. The first (Panel A in Table 5) features all the Big Five personality traits as explanatory variables. The second (Panel B in Table 5) uses five single indicators describing the respondent as hardworking, creative, intelligent, active and thorough.

We find a very weak direct correlation between the Big Five personality traits and employment transitions. On a scale from 1 to 4, where 1 means "not at all” and 4 means “a lot", a one point increase in the degree of openness to experience is associated with a decrease in the probability of staying in full- 
time employment of 2.6 percentage points and correspondingly with an increase in the likelihood of retiring of 2.3 percentage points. The results also show that neuroticism is negatively correlated with the probability of moving to unemployment or out of the labor force, and positively correlated with the probability of part-time employment and retirement (even though the latter correlations are less precisely estimated).

Table 5: Marginal effects of personality traits

\begin{tabular}{|c|c|c|c|c|}
\hline & \multicolumn{4}{|c|}{ Transitions from full-time employed to: } \\
\hline & $\begin{array}{l}\text { Full-time } \\
\text { employed }\end{array}$ & $\begin{array}{l}\text { Part-time } \\
\text { employed }\end{array}$ & Retired & $\begin{array}{c}\text { Out of the LF/ } \\
\text { unemployed }\end{array}$ \\
\hline \multicolumn{5}{|l|}{ Panel A: Big Five } \\
\hline Openness to Experience & $\begin{array}{l}-0.026^{* *} \\
(0.01)\end{array}$ & $\begin{array}{c}0.007 \\
(0.009)\end{array}$ & $\begin{array}{c}0.023^{* *} \\
(0.010)\end{array}$ & $\begin{array}{l}-0.004 \\
(0.005)\end{array}$ \\
\hline Conscientiousness & $\begin{array}{l}-0.002 \\
(0.010)\end{array}$ & $\begin{array}{l}-0.006 \\
(0.008)\end{array}$ & $\begin{array}{c}0.010 \\
(0.009)\end{array}$ & $\begin{array}{l}-0.003 \\
(0.005)\end{array}$ \\
\hline Extraversion & $\begin{array}{c}0.009 \\
(0.010)\end{array}$ & $\begin{array}{l}-0.014 \\
(0.008)\end{array}$ & $\begin{array}{l}-0.005 \\
(0.009)\end{array}$ & $\begin{array}{c}0.009^{*} \\
(0.005)\end{array}$ \\
\hline Agreeableness & $\begin{array}{l}-0.012 \\
(0.01)\end{array}$ & $\begin{array}{c}0.007 \\
(0.009)\end{array}$ & $\begin{array}{c}0.013 \\
(0.010)\end{array}$ & $\begin{array}{l}-0.007 \\
(0.006)\end{array}$ \\
\hline Neuroticism & $\begin{array}{c}0.001 \\
(0.009) \\
\end{array}$ & $\begin{array}{c}0.007 \\
(0.006)\end{array}$ & $\begin{array}{c}0.003 \\
(0.007)\end{array}$ & $\begin{array}{l}-0.012^{* * *} \\
(0.004)\end{array}$ \\
\hline \multicolumn{5}{|l|}{ Panel B: Single Traits } \\
\hline Hardworking & $\begin{array}{l}0_{0.034^{* * *}} \\
(0.009)\end{array}$ & $\begin{array}{l}-0.003 \\
(0.006)\end{array}$ & $\begin{array}{l}-0.025^{* * *} \\
(0.006)\end{array}$ & $\begin{array}{l}-0.006 \\
(0.004)\end{array}$ \\
\hline Creative & $\begin{array}{l}-0.010^{*} \\
(0.006)\end{array}$ & $\begin{array}{c}0.003 \\
(0.004)\end{array}$ & $\begin{array}{l}-0.001 \\
(0.005)\end{array}$ & $\begin{array}{l}0.008^{* * *} \\
(0.003)\end{array}$ \\
\hline Intelligent & $\begin{array}{c}0.002 \\
(0.008)\end{array}$ & $\begin{array}{l}-0.003 \\
(0.005)\end{array}$ & $\begin{array}{c}0.001 \\
(0.006)\end{array}$ & $\begin{array}{c}0.000 \\
(0.004)\end{array}$ \\
\hline Active & $\begin{array}{l}0.015^{* *} \\
(0.007)\end{array}$ & $\begin{array}{c}0.004 \\
(0.005)\end{array}$ & $\begin{array}{l}-0.014^{* *} \\
(0.005)\end{array}$ & $\begin{array}{l}-0.005^{*} \\
(0.003)\end{array}$ \\
\hline Thorough & $\begin{array}{l}-0.002 \\
(0.007)\end{array}$ & $\begin{array}{l}-0.001 \\
(0.005)\end{array}$ & $\begin{array}{c}0.001 \\
(0.005)\end{array}$ & $\begin{array}{c}0.002 \\
(0.003)\end{array}$ \\
\hline
\end{tabular}

As we explain in the appendix, we measure the Big Five personality traits by aggregating single response items into five indexes. ${ }^{3}$ Because of this aggregation, the effect of specific traits, which are perhaps more relevant for labor supply decisions, may be lost. We investigate this possibility by considering a few disaggregated response items. Specifically, we look at the effect of being hardworking and thorough, which both enter the definition of conscientiousness, at the effect of being creative and intelligent, which both enter the definition of openness to experience, and at the effect of being active, which enters the definition of extraversion. The estimated marginal effects in Panel B of Table 5 reveal that individuals who describe themselves as hardworking and active are more likely to remain in fulltime employment and less likely to retire. Being creative is negatively related to the probability of remaining in full-time employment and positively related to the probability of being unemployed or out of the labor force. Intelligence and thoroughness, on the other hand, do not seem to influence labor supply decisions.

\footnotetext{
${ }^{3}$ We follow Duckworth and Weir (2010) to aggregate HRS single response items into the Big Five personality traits.
} 


\subsection{Interaction between job characteristics and personality traits}

The effects of job characteristics and personality traits on employment transitions presented above are robust to including them jointly in the same models and to the introduction of interaction terms between job characteristics and personality traits. The estimation of interaction terms, however, allows us to study how the influence of job characteristics on labor supply decisions varies with the "intensity" of each personality trait. For instance, does the effect of having a difficult or stressful job on the probability of retirement change with the level of neuroticism? In this section, we answer this type of question for a selected set of job characteristics and personality traits (the complete set of results is available upon request). These results address the conjecture that some individuals may have a preference for certain job characteristics over others, that some workers are better able to cope with unpleasant job conditions than others, and that this heterogeneity may be driven by personality traits.

Figure 1: Effect of employer-provided health insurance on employment transitions (by degree of hardworking)
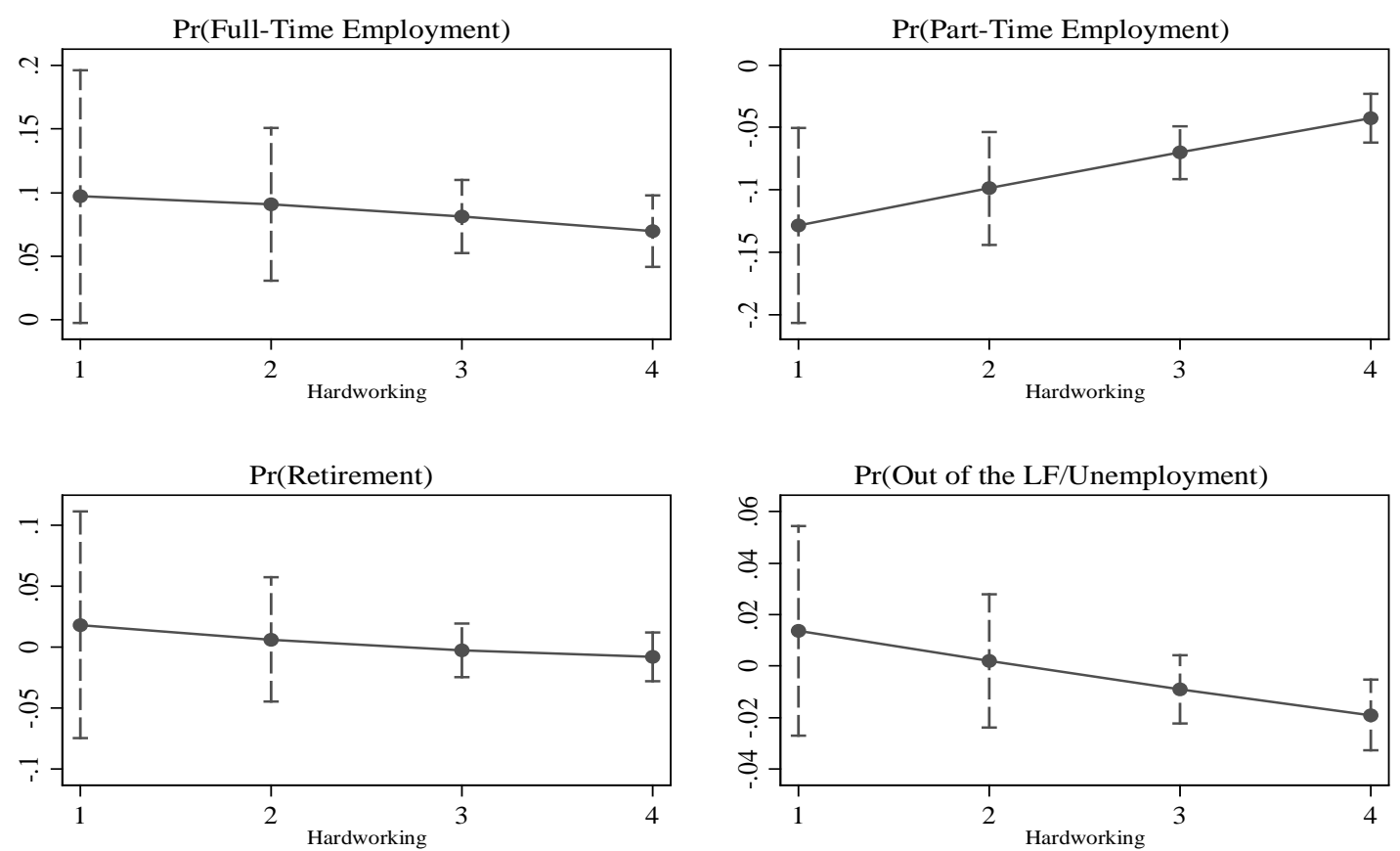

Connected dots represent the point estimates of the marginal effects. The dashed lines indicate $95 \%$ confidence intervals.

The first example in Figure 1 looks at how the impact of having employer-sponsored health insurance on the probability of moving to a different employment status depends on how much the individual defines him/herself as hardworking. We have found above that workers covered by their employer's health insurance plan are more likely to remain in full-time employment. Figure 1 reveals the presence of heterogeneous effects depending on how much individuals define themselves as hardworking. More precisely, the effect of having employer-provided health insurance on the probability of remaining fulltime employed is 3 percentage points weaker at the highest level of hardworking (4) than at the lowest level of hardworking (1). Similarly, the effect on the probability of moving to part-time is 8 percentage points weaker at the highest level of hardworking than at the lowest. In other words, health insurance 
considerations are important drivers of employment transitions, but less so for those who describe themselves as very hardworking.

Figure 2: Effect of hourly wage on employment transitions

(by degree of being active)
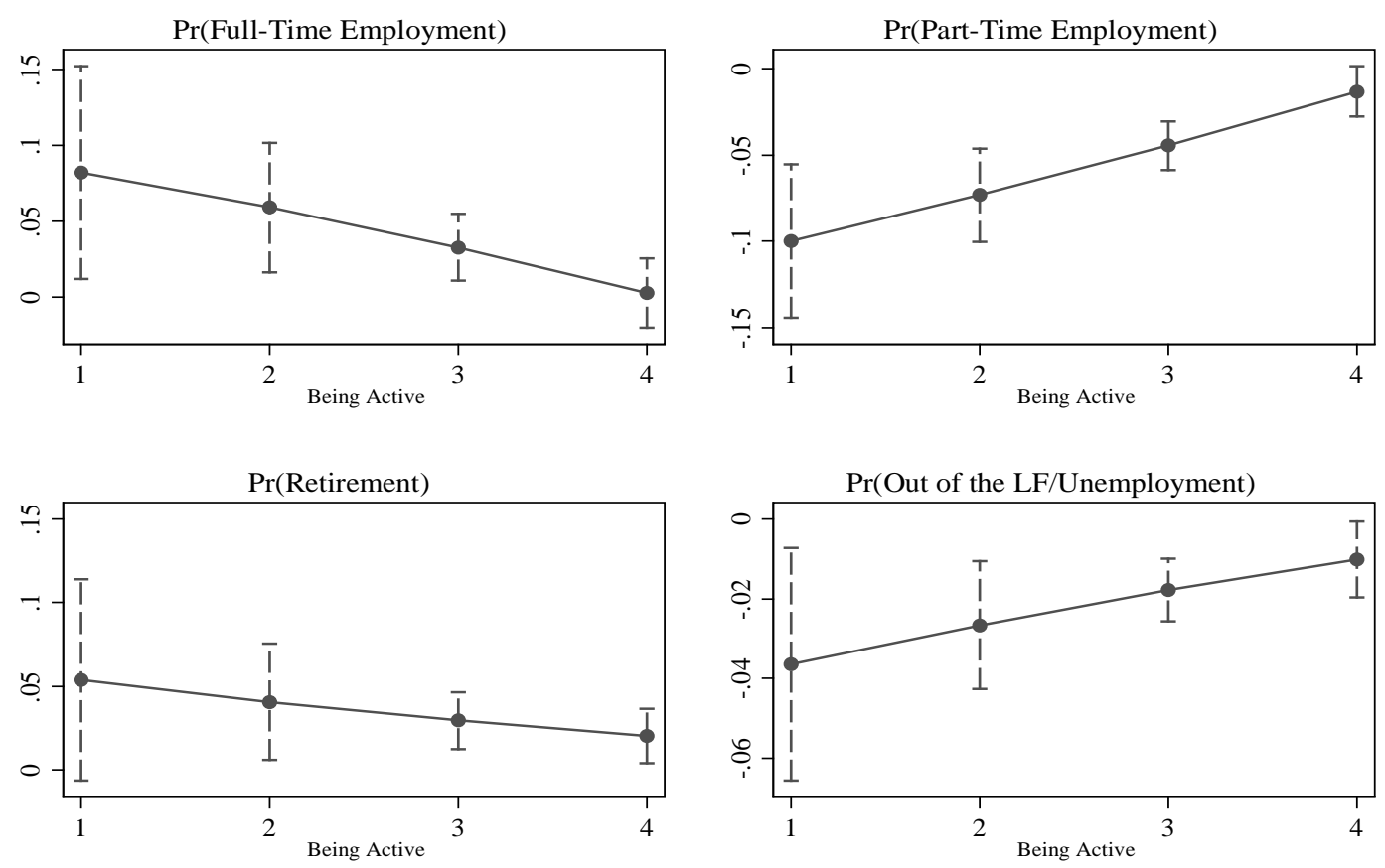

Connected dots represent the point estimates of the marginal effects. The dashed lines indicate 95\% confidence intervals.

Figure 2 shows that financial incentives, as measured by the hourly wage, are less important for employment transitions, the more individuals describe themselves as being active. Indeed, while increasing the hourly wage makes individuals more likely to stay in full-time employment, this effect peters out when moving from the lowest to the highest level of "being active". Similarly, while a higher wage reduces the likelihood of moving to part-time, this effect is ten times as large at the lowest level of being active as it is at the highest level.

In Figure 3, we consider the interaction between age discrimination in the workplace and conscientiousness. The graphs show that as the degree of conscientiousness increases, the negative correlation between age discrimination and probability of remaining in full-time employment weakens. Analogously, the positive association between age discrimination in the workplace and the likelihood of retirement vanishes when moving from the lowest to the highest level of conscientiousness.

A final interesting example is presented in Figure 4. As one would expect, the level of physical effort required by a job is associated with a lower probability of remaining in full-time employment. This effect, however, appears to be heterogeneous depending on whether the individual describes him/herself as being active. Specifically, a 1-step increase on the 4-point scale measuring physical effort is associated with a 5 percentage point decrease in the likelihood that the least active workers remains in 
full-time employment and with only a 1 percentage point decrease in the likelihood that the most active workers remains in full-time employment. These effects are mirrored by the effects on the probability of moving to part-time. In fact, a 1-step increase in the level of physical requirements makes the least active worker 4.5 percentage points more likely to switch to part-time, but does not affect the likelihood that the most active workers transits from full-time to part-time employment.

Figure 3: Effect of age discrimination on employment transitions

(by degree of conscientiousness)
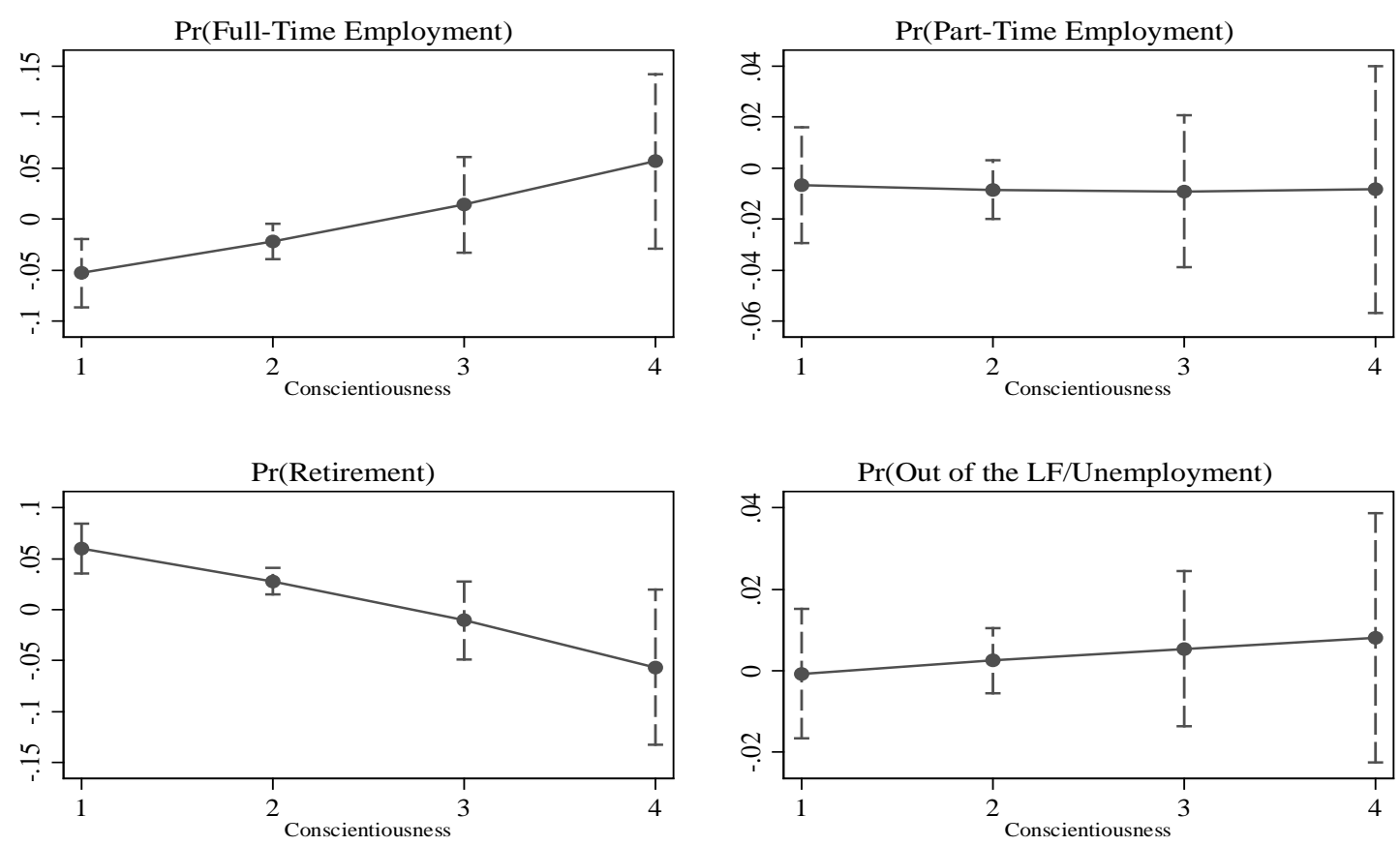

Connected dots represent the point estimates of the marginal effects. The dashed lines indicate $95 \%$ confidence intervals. 
Figure 4: Effect of physical effort on employment transitions

(by degree of being active)
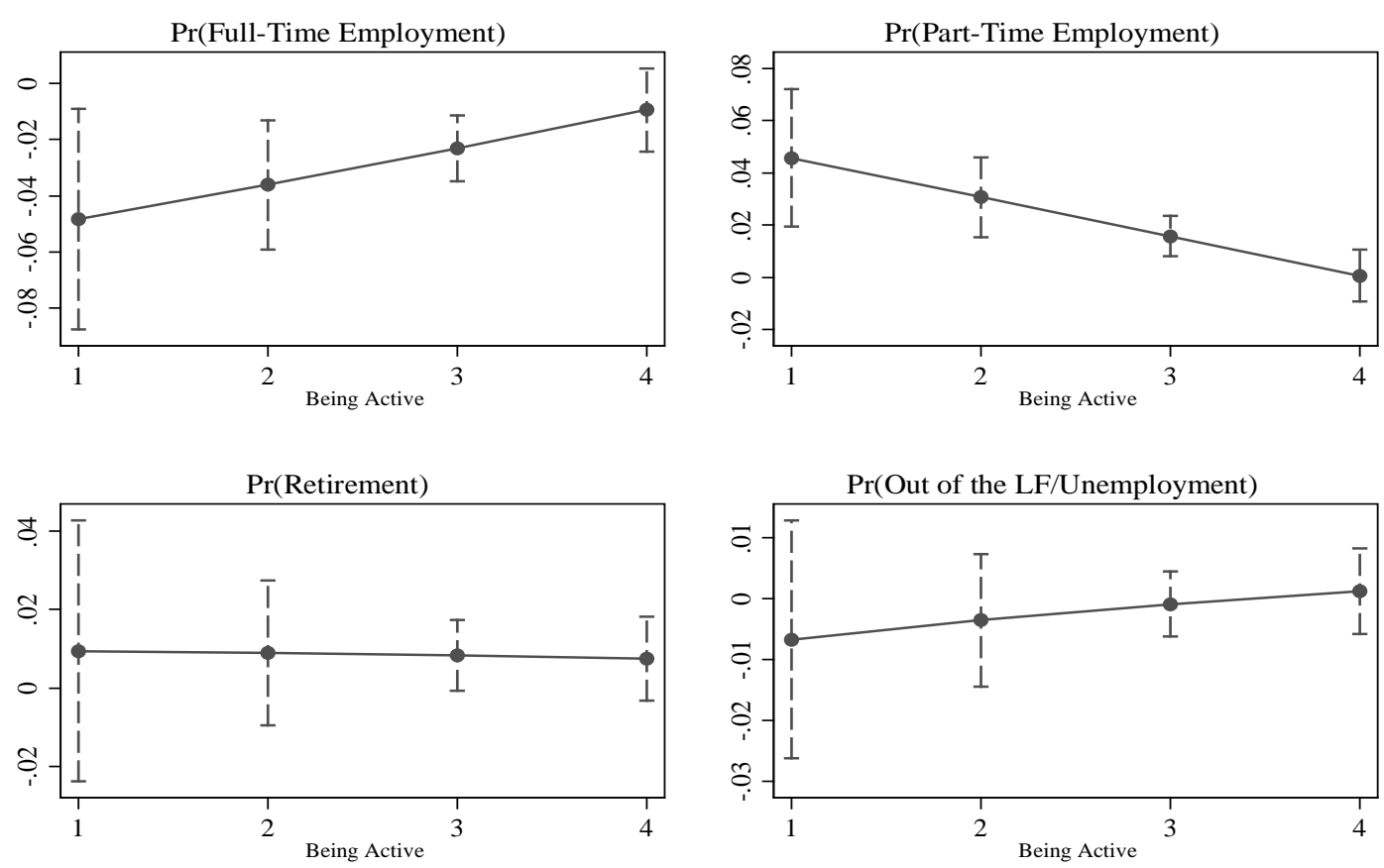

Connected dots represent the point estimates of the marginal effects. The dashed lines indicate $95 \%$ confidence intervals.

\section{The relation between job characteristics and personality traits}

In addition to the direct effects of personality on job transitions in later life, personality may have an indirect effect through its influence on how individuals select into jobs. If individuals with certain personality types have jobs with certain characteristics, and those characteristics affect job transitions, the total effect of personality on, say, retirement decisions is likely to be larger than just the direct effect.

To shed light on the indirect pathway from personality to employment transitions via job characteristics, we study the relation between current job characteristics and the Big Five personality traits, with and without controlling for the base covariates. Note that some of the base covariates (e.g., income, marital status) may themselves be partially determined by personality, so we cannot conclude that the regressions with controls return causal estimates more than those without these controls.

Table 6 and Table 7 present the results for the job characteristics in the core questionnaire and in the leave behind questionnaire, respectively. We have used the same samples for these regressions as in the regressions in section 6 . Each row represents one regression analysis. We report the coefficients of the Big Five personality traits and indicate whether the base covariates are also included, without showing the estimated coefficients for the latter.

With only a few exceptions, each regression has at least one significant personality coefficient. As expected, regressions that control for the base covariates have fewer significant personality coefficients than regressions that do not control for the base covariates. For the characteristics in the core 
questionnaire (Table 6), openness to experience and neuroticism are more often significant and conscientiousness is less often significant. This is somewhat surprising, because conscientiousness has been found most strongly related to economic outcomes in other studies (e.g., Roberts et al., 2007; Hurd et al., 2012).

For interpreting the magnitudes of the coefficients, recall that the personality traits are measured on a scale from 1 to 4 . The first three dependent variables are binary indicators for insurance status and thus the effects are measured in percentage points. Consequently, a 1 point difference in openness to experience is associated with a 5.1 percentage point higher likelihood of having health insurance through the employer, and individuals on one extreme of the openness scale (most open to experience) are three times more likely (or 15.3 percentage points more likely) to have employer-provided health insurance than those on the other extreme of this scale. While this relation vanishes after controlling for the base covariates, a negative and statistically significant association between extraversion and the probability of having employer-sponsored health insurance can be observed with and without additional controls.

The hourly wage is particularly strongly related to the personality variables. Since the dependent variable is the log of the hourly wage, the coefficients can be interpreted as percentages. Thus, we estimate that a one point difference on the openness scale is associated with a 32.7 percent wage difference, and thus the difference associated with the two extremes of the openness scale amounts to almost a 100 percent difference in hourly wage (i.e., a doubling of wage). After controlling for the base covariates, the coefficient drops to about a third of this (partly due to a mechanical effect because log family income is one of the controls), but remains large and statistically significant. Agreeableness exhibits a sizeable, negative association with hourly wage: more agreeable individuals are paid less per hour. Conscientiousness is positively and significantly related to wage, but the estimated coefficient is significantly smaller. 
Table 6: Regression of job characteristics (core questionnaire) on personality traits

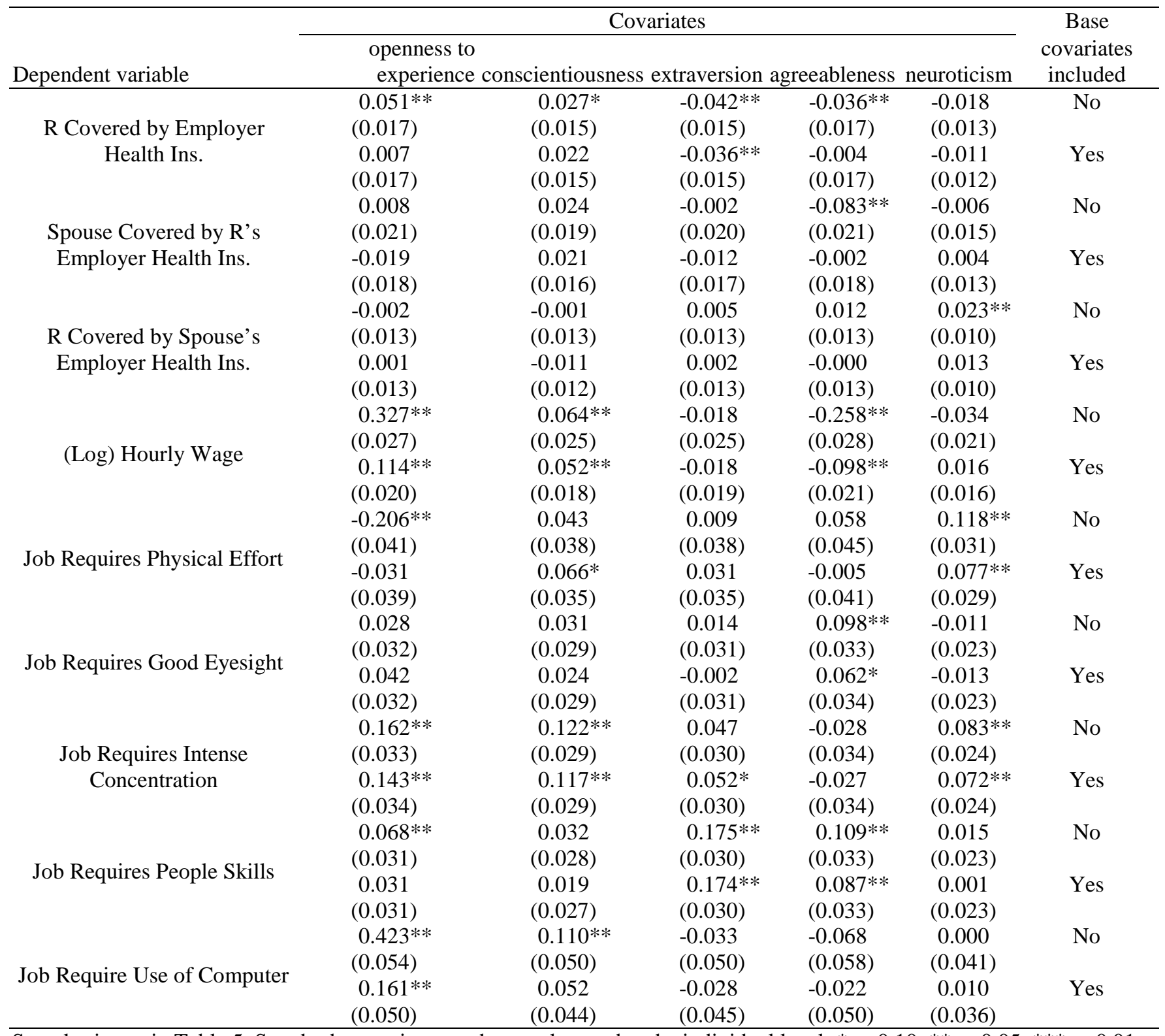

Sample size as in Table 5. Standard errors in parentheses, clustered at the individual level; ${ }^{*} \mathrm{p}<0.10,{ }^{* *} \mathrm{p}<0.05,{ }^{* * *} \mathrm{p}<0.01$.

The binary indicator for not being able to reduce hours of work is positively related to neuroticism. The binary indicator for wanting to but not being able to reduce hours is, instead, negatively related to agreeableness. The remaining dependent variables in Table 6 are measured on a scale from 1 to 4 . Most of the significant coefficients are between 0.1 and 0.2 in magnitude, so the difference between the two extremes on the personality scale is associated with a difference of 0.3-0.6 points on a scale from 1 to 4 of the dependent variable. This is not a negligible effect, but also not a particularly large one. 
Table 6: Regression of job characteristics (core questionnaire) on personality traits (continued)

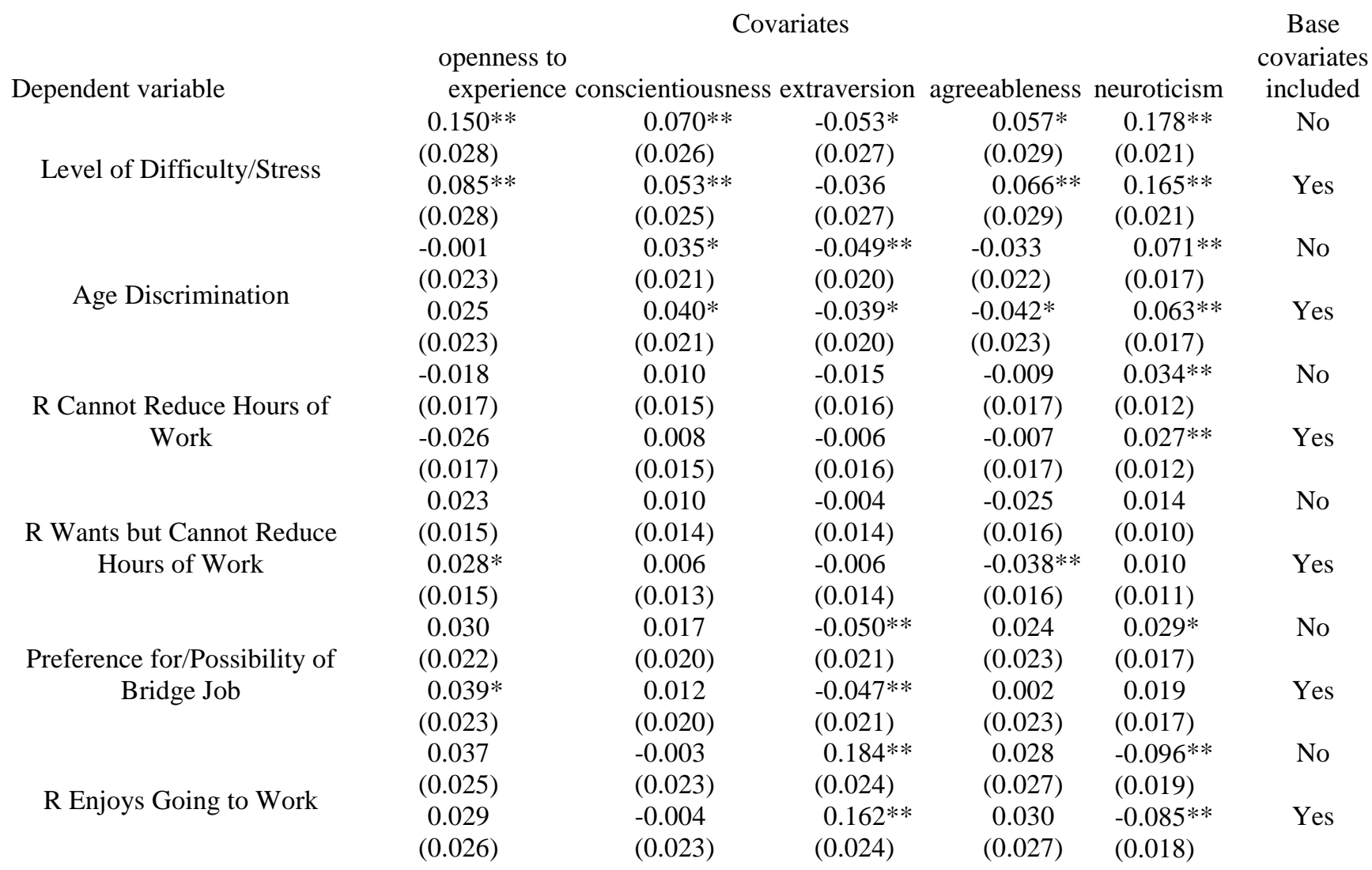

Sample size as in Table 5. Standard errors in parentheses, clustered at the individual level; ${ }^{*} \mathrm{p}<0.10,{ }^{* *} \mathrm{p}<0.05,{ }^{* * *} \mathrm{p}<0.01$.

Looking at some of the salient patterns, we see that openness to experience and conscientiousness are associated with higher wages, more concentration requirement, more computer use, and more difficulty and stress. Agreeableness is associated with lower wages, more required good eyesight, more need for people skills, and more difficulty and stress. Extraversion is associated with a smaller likelihood of having health insurance through the employer, more need for people skills, and less age discrimination. Extraversion is also associated with less desire for a bridge job and with more work enjoyment. Neuroticism is associated with many characteristics: more physical effort, more concentration, a little more age discrimination, more difficulty and stress, a slightly lower likelihood of being able to reduce hours, and less enjoyment of going to work.

The results using the leave behind questions in Table 7 are very different from those using the core questionnaire items in Table 6. Despite much smaller sample sizes, the number of significant coefficients is not smaller. And here the patterns are quite stark: neuroticism is significant in all regressions and extraversion is significant in almost all regressions. Conscientiousness is significant at the $5 \%$ level in only one regression (three more at the $10 \%$ level), agreeableness in two regressions (two more at the $10 \%$ level), and openness to experience in five. This suggests that there is a strong method effect for the kinds of questions in the leave behind questionnaire versus the ones in the core questionnaire, which was also noted in the previous section. 
Table 7: Regression of job characteristics (leave behind questionnaire) on personality traits

\begin{tabular}{|c|c|c|c|c|c|c|}
\hline \multirow{4}{*}{ Dependent variable } & \multicolumn{5}{|c|}{ Covariates } & \multirow{4}{*}{$\begin{array}{c}\text { Base } \\
\text { covariates } \\
\text { included } \\
\text { No }\end{array}$} \\
\hline & \multirow{2}{*}{\multicolumn{4}{|c|}{$\begin{array}{l}\text { openness to } \\
\text { experience conscientiousness extraversion agreeableness }\end{array}$}} & & \\
\hline & & & & & neuroticism & \\
\hline & 0.036 & 0.031 & $-0.271^{* *}$ & -0.052 & $0.341^{* *}$ & \\
\hline \multirow{4}{*}{$\begin{array}{l}\text { Work Interferes with } \\
\text { Personal Life }\end{array}$} & $(0.036)$ & $(0.036)$ & $(0.034)$ & $(0.039)$ & $(0.029)$ & \\
\hline & 0.032 & 0.016 & $-0.241 * *$ & $-0.076 *$ & $0.327 * *$ & Yes \\
\hline & $(0.038)$ & $(0.040)$ & $(0.035)$ & $(0.040)$ & $(0.029)$ & \\
\hline & -0.016 & $-0.043^{*}$ & $-0.154 * *$ & -0.029 & $0.220 * *$ & No \\
\hline \multirow{4}{*}{$\begin{array}{l}\text { Personal Life Interferes } \\
\text { with Work }\end{array}$} & $(0.026)$ & $(0.025)$ & $(0.025)$ & $(0.028)$ & $(0.021)$ & \\
\hline & 0.004 & $-0.078 * *$ & $-0.122 * *$ & $-0.079 * *$ & $0.215^{* *}$ & Yes \\
\hline & $(0.027)$ & $(0.028)$ & $(0.025)$ & $(0.028)$ & $(0.021)$ & \\
\hline & $0.114^{* *}$ & $0.103^{*}$ & $-0.126^{* *}$ & -0.047 & $0.496 * *$ & No \\
\hline \multirow{4}{*}{ Treated Unfairly at Work } & $(0.058)$ & $(0.055)$ & $(0.055)$ & $(0.059)$ & $(0.047)$ & \\
\hline & $0.188 * *$ & 0.026 & -0.060 & $-0.126 * *$ & $0.484 * *$ & Yes \\
\hline & $(0.060)$ & $(0.060)$ & $(0.057)$ & $(0.062)$ & $(0.046)$ & \\
\hline & $0.078 * *$ & -0.022 & $0.082 * *$ & $-0.063 *$ & $-0.144^{* *}$ & No \\
\hline \multirow{4}{*}{ Rewards and Recognition } & $(0.036)$ & $(0.036)$ & $(0.035)$ & $(0.037)$ & $(0.028)$ & \\
\hline & 0.046 & -0.017 & $0.059 *$ & -0.038 & $-0.124 * *$ & Yes \\
\hline & $(0.036)$ & $(0.038)$ & $(0.034)$ & $(0.036)$ & $(0.028)$ & \\
\hline & $-0.103 * *$ & -0.041 & $-0.125 * *$ & 0.048 & $0.117 * *$ & No \\
\hline \multirow{4}{*}{ Poor Job Prospects } & $(0.034)$ & $(0.030)$ & $(0.032)$ & $(0.032)$ & $(0.025)$ & \\
\hline & $-0.069 * *$ & $-0.061^{*}$ & $-0.101 * *$ & 0.029 & $0.108 * *$ & Yes \\
\hline & $(0.034)$ & $(0.032)$ & $(0.031)$ & $(0.032)$ & $(0.025)$ & \\
\hline & -0.012 & 0.025 & $-0.089 * *$ & -0.032 & $0.145^{* *}$ & No \\
\hline \multirow{4}{*}{ Job is Demanding } & $(0.026)$ & $(0.024)$ & $(0.025)$ & $(0.026)$ & $(0.020)$ & \\
\hline & -0.003 & 0.011 & $-0.069 * *$ & -0.043 & $0.133^{* *}$ & Yes \\
\hline & $(0.026)$ & $(0.025)$ & $(0.024)$ & $(0.027)$ & $(0.019)$ & \\
\hline & -0.009 & 0.035 & $-0.149 * *$ & -0.027 & $0.283^{* *}$ & No \\
\hline \multirow{3}{*}{$\begin{array}{l}\text { Bothered or Upset on the } \\
\text { Job }\end{array}$} & $(0.043)$ & $(0.040)$ & (0.039) & $(0.042)$ & $(0.031)$ & \\
\hline & 0.014 & 0.016 & $-0.118 * *$ & -0.043 & $0.268 * *$ & Yes \\
\hline & $(0.041)$ & $(0.042)$ & (0.037) & $(0.042)$ & $(0.030)$ & \\
\hline \multirow{4}{*}{ Satisfied with the Job } & 0.028 & 0.031 & $0.150^{* *}$ & 0.021 & $-0.159 * *$ & No \\
\hline & $(0.047)$ & $(0.047)$ & $(0.046)$ & $(0.048)$ & $(0.036)$ & \\
\hline & -0.025 & 0.025 & $0.117^{* *}$ & 0.031 & $-0.124^{* *}$ & Yes \\
\hline & $(0.040)$ & $(0.041)$ & $(0.039)$ & $(0.042)$ & $(0.030)$ & \\
\hline
\end{tabular}

Sample size as in Table 4. Standard errors in parentheses, clustered at the individual level; ${ }^{*} \mathrm{p}<0.10,{ }^{* *} \mathrm{p}<0.05,{ }^{* * *} \mathrm{p}<0.01$.

Looking at the signs of these coefficients, we see that neuroticism is negatively related to job conditions (positive coefficients for negative characteristics, negative coefficients for positive characteristics), whereas extraversion is positively related to job conditions (positive coefficients for positive characteristics, negative for negative characteristics). Openness to experience is positively related to mistreatment in the workplace and work recognition/rewards (though only significant if not controlling for the base covariates) and negatively related to poor prospects. Thus, this trait does not appear to be systematically related to "better" or "worse" work environments. Conscientious and agreeable individuals are less likely to report that personal life interferes with work. 
Overall, the sizes of the significant coefficients in Table 7 are typically between 0.1 and 0.2 . Hence, going from one extreme to the other on the personality scale leads to a difference of 0.3-0.6 points on the scale of the dependent variable. Again, this is a noticeable effect, yet not very large. However, the effects of extraversion and neuroticism are double this: going from $(1,4)$ to $(4,1)$ leads to change of 0.61.2 points on the scale of the dependent variable.

\section{Discussion}

In this paper, we study to what extent job characteristics, job satisfaction, and personality traits are associated with labor force transitions at older ages. Specifically, we take individuals age 51-79 in the Health and Retirement Study (HRS) who are full-time employed and examine whether their employment transitions across two consecutive waves (approximately two years apart) are related to a large number of job characteristics, their Big Five personality traits (openness to experience, conscientiousness, extraversion, agreeableness, and neuroticism or emotional stability), and interactions of these, while controlling for a rich set of social and demographic covariates.

We find that job characteristics are indeed strongly predictive of labor force transitions. Specifically, respondents covered by an employer-provided health insurance plan are more likely to remain full-time employed, and less likely to move to part-time or out of the labor force. Similarly, a higher hourly wage is associated with a higher probability of remaining in full-time employment and a lower probability of moving to part-time or out of the labor force. Interestingly, individuals with higher wages are also more likely to retire. Among non-monetary factors, we document that physical strains increase the chances of either switching to part-time or retiring altogether, while the use of a computer is associated with a higher probability of remaining full-time employed. We also find that age discrimination in the workplace and flexibility in terms of hours of work play a key role in shaping labor supply decisions at older ages. Furthermore, individuals who perceive that their work activities interfere with their personal life are less likely to transit from full-time employment to retirement. Finally, the quality of the relationship with coworkers and supervisors has a strong, negative impact on the likelihood that fulltime employees switch to part-time or move out of the labor force.

We do not observe a significant, direct effect of personality traits on labor force transitions. The only trait that is significantly related to labor supply decisions at older ages is openness to experience. Specifically, we estimate that the probability of remaining in full-time employment decreases with the level of openness to experience, while the probability of retirement increases. On the other hand, we show that the influence of job characteristics on labor force transitions varies with the "intensity" of each personality trait. This result points to the fact that individuals' ability to cope with unpleasant job conditions and work-related stress is highly heterogeneous and plausibly driven by personality traits.

We further investigate the extent to which job characteristics themselves can be directly explained by personality traits and find numerous significant relationships. Especially openness to experience and neuroticism are often significantly related to job characteristics and, somewhat surprisingly in the light of the extant literature on personality and economic outcomes, conscientiousness has relatively less predictive power. The magnitudes of the significant effects are usually moderately large, but in some cases very large. In particular, openness to experience is strongly related to hourly wage and to computer use on the job. Neuroticism is negatively related to desirable job characteristics. We also find evidence suggestive of a so-called method effect, given that neuroticism and extraversion have very strong and 
significant patterns in the leave-behind questionnaire and much less so in the core questionnaire, where different types of response categories are used.

Although our results are suggestive, we cannot claim that they are estimates of causal effects. First, besides personality traits, other unobservable individual preferences may affect both selection into jobs with specific characteristics and labor supply decisions at older ages. Second, job separations during economic booms are typically voluntary, followed by continued full-time employment, whereas, during a recession, job separations are typically involuntary, followed by unemployment, disability claims, involuntary retirement, or otherwise not being in the labor force (Akerlof et al., 1988). Thus, individual labor force transitions are likely to be different during an economic boom (supply driven) than during a recession (demand driven). We control for this to some extent by using wave dummies (we have also experimented with interacting these with explanatory variables of interest), but we cannot claim to have estimated causal pathways from job conditions to employment transitions.

While the literature on the relation between personality and economic outcomes (such as earnings, wealth conditional on earnings, and economic preparation for retirement) generally finds that conscientiousness is the strongest predictor of economic outcomes, our estimates suggest that some of the other personality traits are more important for labor force transitions. However, since our models include measures of financial preparedness for retirement (e.g., family income and wealth), which is likely driven by conscientiousness, the genuine effect of conscientiousness on labor force transitions may have been controlled away. Our results can be used to compute tentative decompositions of the effects of job characteristics and personality on labor force transitions into (1) the indirect effect of personality on labor force transitions through job characteristics, (2) the direct effect of personality on labor force transitions, and (3) the direct effect of the part of job characteristics that is not explained by personality. We leave this for future research,

An important limitation of our analysis is that our regressions do not account for cognitive skills. Cognitive ability is strongly related to economic outcomes and it is likely correlated with job characteristics, and to a lesser extent with personality traits. Hence, including cognitive ability in the models may lead to different findings. We will incorporate one or more measures of cognitive skills to assess the robustness of our results.

Our study uses relatively simple cross-sectional choice models, which do not take into account the intrinsic dynamic nature of labor supply choices. Such models give valuable insights and are highly useful in relatively stable economic contexts and policy environments. However, it has been documented in the literature that so-called "structural" models, such as the ones of Gustman and Steinmeier (1986), Rust and Phelan (1997), or French (2005), which formalize individuals’ forward looking behavior through expected lifetime utility maximization, replicate stylized facts about retirement and Social Security claiming well, and can, therefore, be successfully used to evaluate the impact of policy interventions. An important step toward the development of more realistic models is to embed the findings of this paper into such analytical frameworks. Some hints of how findings from personality theory can be incorporated into structural economic models have been given in Almlund et al. (2011). The challenge for future research is to extend structural models of retirement to include economic incentives as well as personality and non-monetary job characteristics. 


\section{References}

Akerlof, G. A., Rose, A. K., and Yellen, J. L. (1988). Job switching and job satisfaction in the U.S. labor market. Brookings Papers on Economic Activity, 1988, pp. 495-582.

Almlund, M., Duckworth, A. L., Heckman, J., \& Kautz, T. (2011). Personality psychology and economics. Handbook of the Economics of Education, 4, pp. 1-181.

Bartel A. (1982). Wages, Nonwage Job Characteristics and Labor Mobility. Industrial and Labor Relations Review, 35(4), pp. 578-589.

Blekesaune M. and Solem P.E. (2005). Working Conditions and Early Retirement. Research on Aging, 27(1), pp. 3-30.

Chan S. and Stevens A.H. (2008), "Is Retirement Being Remade? Developments in Labor Market Patterns at Older Ages.” In J. Ameriks and O.S. Mitchell (Eds.), Recalibrating Retirement Spending and Saving (pp. 13-28). Oxford, UK: Oxford University Press.

Chien, S., et al. (2013). RAND HRS Data Documentation, Version M. Santa Monica, CA: RAND Center for the Study of Aging.

Cobb-Clark D. A., and Schurer, S. (2012). The stability of big-five personality traits. Economics Letters, 115, pp. 11-15.

Coile C. and Levine P. (2010), Reconsidering Retirement: How Losses and Layoffs Affect Older Workers, The Brookings Institution, Washington, DC.

Crespo L. (2006), “Caring for Parents and Employment Status of European Mid-Life Women,” Working Paper Center for Monetary and Financial Studies (CEMFI), Madrid, Spain.

Currie J. and Madrian B. (1999), "Health, Health Insurance and the Labor Market”. In Handbook of Labor Economics, D. Card and O. Ashenfelter (eds). Amsterdam: North Holland, pp. 3309-3407.

Duckworth, A.L, and Weir, D. (2010). Personality, Lifetime Earnings, and Retirement Wealth. Working Paper No. WP 2010-235. Ann Arbor, MI: University of Michigan Retirement Research Center.

Duckworth, A.L, Weir, D., Tsukayama, E., and Kwok, D. (2012).Who does well in life? Conscientious adults excel in both objective and subjective success. Manuscript.

Fevang E., Kverndokk S., and Røed K. (2008), “Informal Care and Labor Supply,” Working Paper 8, Health Economics Research Programme at the University of Oslo (HERO).

French, E. (2005). The effects of health, wealth, and wages on labour supply and retirement behaviour. Review of Economic Studies, 72, pp. 397-427.

García Pérez J.I. and Sánchez Martín A.R. (2008), "Social Security and the Search Behaviour of Workers Approaching Retirement,” Working Paper Econ 08 03, Universidad Pablo Olavide, Sevilla, Spain.

Gruber J. and Wise D.A. (eds.) (1999), Social Security and Retirement Around the World, Chicago, IL: University of Chicago Press.

Gruber J. and Wise D.A. (eds.) (2004), Social Security Programs and Retirement around the World: Micro-Estimation, Chicago, IL: University of Chicago Press.

Gustman A.L. and Steinmeier T.L. (1984), "Partial Retirement and the Analysis of Retirement Behavior,” Industrial and Labor Relations Review, 37(3), pp. 403-415.

Gustman, A.L., \& Steinmeier, T.L. (1986). A structural retirement model. Econometrica, 54, pp. 555584.

Hayward, M., Grady, W., Hardy M, and Sommers, D. (1989), “Occupational Influences on Retirement, Disability, and Death,” Demography, 26, pp. 393-409.

Hurd M.D. (1990), "Research on the Elderly: Economic Status, Retirement, and Consumption and Saving,” Journal of Economic Literature, 28(2), pp. 565-637. 
Hurd M.D. and McGarry, K. (1993), "The Relationship between Job Characteristics and Retirement," Working Paper No. 4558. Cambridge, MA: National Bureau of Economic Research.

Hurd, M.D., Duckworth, A.L., Rohwedder, S., and Weir, D. R. (2012). Personality Traits and Economic Preparation for Retirement. Working Paper No. WP 2012-279. Ann Arbor, MI: University of Michigan Retirement Research Center.

John, O.P., \& Srivastava, S. (1999). The Big Five trait taxonomy: history, measurement and theoretical perspectives. In: L.A. Pervin \& O.P. John (Eds.), Handbook of Personality: Theory and Research (2nd ed.; pp. 102-138). New York, NY: Guilford Press.

Lucas, R.E., \& Donnellan, M.B. (2011). Personality Development Across the Life Span: Longitudinal Analyses With a National Sample From Germany. Journal of Personality and Social Psychology, 101, pp. 847-861.

Lumsdaine R. and Mitchell O. (1999), "New Developments in the Economic Analysis of Retirement," in Handbook of Labor Economics, D. Card and O. Ashenfelter, eds., Amsterdam: North Holland, pp. 3261-3307.

Maestas N. (2010), "Back to Work Expectations and Realizations of Work after Retirement," The Journal of Human Resources, 45(3), pp. 718-748.

Poropat, A.E. (2009). A meta-analysis of the five-factor model of personality and academic performance. Psychological Bulletin, 135, pp. 322-338.

Roberts, B.W., Kuncel, N.R., Shiner, R., Caspi, A., \& Goldberg, L.R. (2007). The power of personality: The comparative validity of personality traits, socioeconomic status, and cognitive ability for predicting important life outcomes. Perspectives on Psychological Science, 2, pp. 313-345.

Ruhm, C.J. (1990), "Bridge Jobs and Partial Retirement,” Journal of Labor Economics, 8(4), pp. 482501.

Rust, J., \& Phelan, C. (1997). How Social Security and Medicare affect retirement behavior in a world of incomplete markets. Econometrica, 65, pp. 781-831.

Specht, J., Egloff, B., \& Schmukle, S.C. (2011). Stability and Change of Personality Across the Life Course: The Impact of Age and Major Life Events on Mean-Level and Rank-Order Stability of the Big Five. Journal of Personality and Social Psychology, 101, pp. 862-882. 


\section{Appendix: Data construction}

In this appendix, we describe how we construct the key variables of interest. As stated in the text, all data are taken from the Health and Retirement Study (HRS), starting with the main RAND version of the HRS (RAND HRS version $M$ ) and using variables from the RAND FAT files, which collect all the separate modules, as necessary. The two HRS modules that the FAT variables originate from are the employment module (section $\mathrm{J}$ ) and the leave-behind questionnaire.

\section{A.1 Job characteristics from the core questionnaire}

We take the following items from the RAND HRS ( $\mathrm{w}=6,7,8,9$, or 10 is the wave number):

\begin{tabular}{|l|l|l|l|}
\hline Variable & Description & Code & Name in Result Tables \\
\hline RwCOVR & R covered by R employer plan & Binary & R Covered by Employer Health Ins. \\
\hline SwCOVR & Spouse covered by R employer plan & Binary & Spouse Covered by R's Employer Health Ins. \\
\hline RwCOVS & R covered by spouse's employer plan & Binary & R Covered by Spouse's Employer Health Ins. \\
\hline RwWGIHR & Imputed wage rate (hourly) & Continuous & (Log) Hourly Wage \\
\hline
\end{tabular}

We take the following items from the HRS core questionnaire (section J):

\begin{tabular}{|l|l|c|c|}
\hline Variable & Question & Code & Name in Result Tables \\
\hline J234 & $\begin{array}{l}\text { Not counting overtime hours, could you reduce the } \\
\text { number of paid hours in your regular work schedu }\end{array}$ & Binary & R Cannot Reduce Hours of Work \\
\hline J235 & $\begin{array}{l}\text { Would you like to do so even if your earnings were } \\
\text { reduced in the same proportion? }\end{array}$ & Binary & R Wants but Cannot Reduce Hours of Work \\
\hline
\end{tabular}

The items below are taken from the HRS core questionnaire (section J). All items are preceded by the introduction "I'll read some statements that are true for some people's jobs but not for other people's jobs. Thinking of your job, please tell me how often these statements are true” and use the scale $1=$ all or almost all of the time; $2=$ most of the time; $3=$ some of the time; $4=$ none or almost none of the time.

\begin{tabular}{|l|l|l|l|}
\hline Variable & Question & Code & Part of which index \\
\hline J538 & My job requires lots of physical effort & 1 to 4 & Job Requires Physical Effort \\
\hline J539 & My job requires lifting heavy loads & 1 to 4 & Job Requires Physical Effort \\
\hline J540 & My job requires stooping, kneeling, or crouching & 1 to 4 & Job Requires Physical Effort \\
\hline J541 & My job requires good eyesight & 1 to 4 & Job Requires Good Eyesight \\
\hline J542 & My job requires intense concentration or attention & 1 to 4 & Job Requires Intense Concentration \\
\hline J543 & My job requires skills in dealing with other people & 1 to 4 & Job Requires People Skills \\
\hline J544 & My job requires to work with computers & 1 to 4 & Job Require Use of Computer \\
\hline
\end{tabular}


We reverse the scale for all these items so that 1 is "None or almost none of the time" and 4 is "All or almost all of the time”. We combine J538, J539, and J540 into the single index "Job Requires Physical Effort”. In doing so we average the scores across the items included in the index and set the final index to missing if more than half of the items have missing values.

The items below are taken from the HRS core questionnaire (section J). All items are preceded by the introduction "Here are some statements that are true for some people's jobs but not for other people's jobs. Again, thinking of your job, please indicate how much you agree or disagree with each statement” and use the scale 1 = strongly agree; 2 = agree; 3 = disagree; 4 = strongly disagree.

\begin{tabular}{|l|l|l|l|}
\hline Variable & Question & Code & Part of which index \\
\hline J546 & My job requires to do more difficult things than it used to & 1 to 4 & Level of Difficulty/Stress \\
\hline J547 & My job requires a lot of stress & 1 to 4 & Level of Difficulty/Stress \\
\hline J548 & $\begin{array}{l}\text { In decisions about promotions, my employer gives younger } \\
\text { people preference over old people }\end{array}$ & 1 to 4 & Age Discrimination \\
\hline J549 & $\begin{array}{l}\text { My co-workers make older workers feel that they ought to } \\
\text { retire before age 65 }\end{array}$ & 1 to 4 & Age Discrimination \\
\hline J550 & $\begin{array}{l}\text { As I get older, I would prefer to gradually reduce the hours I } \\
\text { work on this job, keeping my pay per hour the same }\end{array}$ & 1 to 4 & Preference for/Possibility of Bridge Job \\
\hline J551 & $\begin{array}{l}\text { My employer would let older workers move to a less } \\
\text { demanding job with less pay if they wanted to }\end{array}$ & 1 to 4 & Preference for/Possibility of Bridge Job \\
\hline J552 & \begin{tabular}{l} 
I really enjoy going to work \\
\hline
\end{tabular}
\end{tabular}

We reverse the scale for all these items so that 1 is "None or almost none of the time" and 4 is "All or almost all of the time”. We combine J546 and J547 into the single index "Level of Difficulty/Stress"; J548 and J549 into the single index "Age Discrimination"; J550 and J551 into the single index "Preference for/Possibility of Bridge Job". In doing so, we average the scores across the items included in the index and set the final index to missing if more than half of the items have missing values.

All questions about job characteristics are only asked of those respondents who are working for pay at the time of the interview. Since we select full-time employees in wave $t$ and focus on their employment transitions from wave $t$ to wave $t+1$, we use individual job characteristics observed in wave $t$ when all individuals in the selected sample are in full-time employment. 


\section{A.2 Job characteristics from the leave behind questionnaire}

The items below are taken from the HRS leave behind questionnaire. These questions are asked in waves 8 , 9, and 10 (2006, 2008, and 2010). All items use the scale 1 = rarely; 2 = sometimes; 3 = often; $4=$ most of the time.

\begin{tabular}{|l|l|c|l|}
\hline Variable & Question & Code & Part of which index \\
\hline Q48a & $\begin{array}{l}\text { My work schedule makes it difficult to fulfill personal } \\
\text { responsibilities }\end{array}$ & 1 to 4 & Work Interferes with Personal Life \\
\hline Q48b & $\begin{array}{l}\text { Because of my job, I don't have the energy to do things } \\
\text { with my family or other important people in my life }\end{array}$ & 1 to 4 & Work Interferes with Personal Life \\
\hline Q48c & $\begin{array}{l}\text { Job worries or problems distract me when I am not at } \\
\text { work }\end{array}$ & 1 to 4 & Work Interferes with Personal Life \\
\hline Q48d & $\begin{array}{l}\text { My home life keeps me from getting work done on time } \\
\text { on my job }\end{array}$ & 1 to 4 & Personal Life Interferes with Work \\
\hline Q48e & $\begin{array}{l}\text { My family or personal life drains me of the energy I need } \\
\text { to do my job }\end{array}$ & 1 to 4 & Personal Life Interferes with Work \\
\hline Q48f & $\begin{array}{l}\text { I am preoccupied with personal responsibilities while I } \\
\text { am at work }\end{array}$ & 1 to 4 & Personal Life Interferes with Work \\
\hline Q48g & $\begin{array}{l}\text { My work leaves me enough time to attend to my personal } \\
\text { responsibilities }\end{array}$ & 1 to 4 & Work Interferes with Personal Life \\
\hline Q48h & $\begin{array}{l}\text { My work gives me energy to do things with my family } \\
\text { and other important people in my life }\end{array}$ & 1 to 4 & Work Interferes with Personal Life \\
\hline Q48i & Because of my job, I am in a better mood at home & 1 to 4 & Work Interferes with Personal Life \\
\hline Q48j & $\begin{array}{l}\text { My personal responsibilities leave me enough time to do } \\
\text { my job }\end{array}$ & 1 to 4 & Personal Life Interferes with Work \\
\hline Q48k & $\begin{array}{l}\text { My family or personal life gives me energy to do my job } \\
\text { personal life }\end{array}$ & 1 to 4 & Personal Life Interferes with Work \\
\hline Q48l & $\begin{array}{l}\text { I am in atter mood at work because of my family or } \\
\text { to } 4\end{array}$ & Personal Life Interferes with Work \\
\hline
\end{tabular}

We combine Q48a, Q48b, Q48c, Q48g (reversed scale), Q48h (reversed scale), and Q48i (reversed scale) into the single index "Work Interferes with Personal Life". We combine Q48d, Q48e, Q48f, Q48j (reversed scale), Q48k (reversed scale), and Q48l (reversed scale) into the single index "Personal Life Interferes with Work". In doing so we average the scores across the items included in the index and set the final index to missing if more than half of the items have missing values.

The items below are taken from the HRS leave behind questionnaire. These questions are asked in waves 8,9 , and 10 (2006, 2008, and 2010). All items use the scale $1=$ never; $2=$ less than once a year; 3 $=\mathrm{a}$ few times a year; $4=\mathrm{a}$ few times a month; $5=$ at least once a week; $6=$ almost every day. 


\begin{tabular}{|l|l|c|l|}
\hline Variable & Question & Code & Part of which index \\
\hline Q49a & $\begin{array}{l}\text { How often are you unfairly given the tasks at work that no one else } \\
\text { wants to do? }\end{array}$ & 1 to 6 & Treated Unfairly at Work \\
\hline Q49b & How often are you watched more closely than others? & 1 to 6 & Treated Unfairly at Work \\
\hline Q49c & $\begin{array}{l}\text { How often are you bothered by your supervisor or coworkers making } \\
\text { slurs or jokes about women or racial or ethnic groups? }\end{array}$ & 1 to 6 & Treated Unfairly at Work \\
\hline Q49d & $\begin{array}{l}\text { How often do you feel that you have to work twice as hard as others at } \\
\text { work? }\end{array}$ & 1 to 6 & Treated Unfairly at Work \\
\hline Q49e & $\begin{array}{l}\text { How often do you feel that you are ignored or not taken seriously by } \\
\text { your boss? }\end{array}$ & 1 to 6 & Treated Unfairly at Work \\
\hline Q49f & How often have you been unfairly humiliated in front of others at work? & 1 to 6 & Treated Unfairly at Work \\
\hline
\end{tabular}

We combine items from Q49a to Q49f into the single index “Treated Unfairly at Work”. In doing so we average the scores across the items included in the index and set the final index to missing if more than half of the items have missing values.

The items below are taken from the HRS leave behind questionnaire. These questions are asked in waves 7, 8, 9, and 10 (2004, 2006, 2008, and 2010). All items use the scale $1=$ strongly disagree; $2=$ disagree; 3 = agree; 4 = strongly disagree.

\begin{tabular}{|c|c|c|c|}
\hline Variable & Question & Code & Part of which index \\
\hline Q50a & All things considered, I am satisfied with my job & 1 to 4 & Satisfied with the Job \\
\hline Q50c & I receive the recognition I deserve for my work & 1 to 4 & Rewards and Recognition \\
\hline Q50d & My salary is adequate & 1 to 4 & Rewards and Recognition \\
\hline Q50e & My job promotion prospects are poor & 1 to 4 & Poor Job Prospects \\
\hline Q50f & My job security is poor & 1 to 4 & Poor Job Prospects \\
\hline Q50g & I am under constant time pressure due to a heavy workload & 1 to 4 & Job is Demanding \\
\hline Q50h & I have very little freedom to decide how I do my work & 1 to 4 & Job is Demanding \\
\hline Q50i & I have the opportunity to develop new skills & 1 to 4 & Job is Demanding \\
\hline Q50j & I receive adequate support in difficult situations & 1 to 4 & Job is Demanding \\
\hline Q50k & At work, I feel I have control over what happens in most situations & 1 to 4 & Job is Demanding \\
\hline Q501 & Considering the things I have to do at work, I have to work very fast & 1 to 4 & Job is Demanding \\
\hline Q50m & I often feel bothered or upset in my work & 1 to 4 & Bothered or Upset on the Job \\
\hline Q50n & In my work I am free from conflicting demands that others make & 1 to 4 & Job is Demanding \\
\hline
\end{tabular}


We combine items Q50c and Q50d into the single index "Rewards and Recognition"; items Q50e and Q50f into the single index "Poor Job Prospects”; and items Q50g, Q50h, Q50i (reversed scale), Q50j (reversed scale), Q50k (reversed scale), Q50l, and Q50n (reversed scale) into the single index "Job is Demanding”. In doing so, we average the scores across the items included in the index and set the final index to missing if more than half of the items have missing values.

The items below are taken from the HRS leave behind questionnaire. These questions are asked in waves 9 and 10 (2008, and 2010). All items use the scale 1 = strongly disagree; 2 = disagree; 3 = agree; 4 = strongly disagree.

\begin{tabular}{|c|c|c|c|}
\hline Variable & Question & Code & Part of which index \\
\hline Q50q & I have a lot to say about what happens on my job & 1 to 4 & A Lot to Say about What Happens at Work \\
\hline Q50s & $\begin{array}{l}\text { I have the training opportunity I need to perform my job } \\
\text { safely and competently }\end{array}$ & 1 to 4 & Good Training Opportunities \\
\hline Q50t & $\begin{array}{l}\text { The people I work with can be relied on when I need } \\
\text { help }\end{array}$ & 1 to 4 & Good Relationship with Coworkers \\
\hline Q50u & $\begin{array}{l}\text { My coworkers listen to me when I need to talk about } \\
\text { work-related problems }\end{array}$ & 1 to 4 & Good Relationship with Coworkers \\
\hline Q50v & My coworkers help me with difficult tasks at work & 1 to 4 & Good Relationship with Coworkers \\
\hline Q50w & My coworkers help me in crisis situations at work & 1 to 4 & Good Relationship with Coworkers \\
\hline Q50x & My supervisor is helpful to me & 1 to 4 & Good Relationship with Supervisors \\
\hline Q50y & $\begin{array}{l}\text { My supervisor is willing to extend himself/herself to } \\
\text { help me perform my job }\end{array}$ & 1 to 4 & Good Relationship with Supervisors \\
\hline Q50z & $\begin{array}{l}\text { My supervisor takes pride in my accomplishments at } \\
\text { work }\end{array}$ & 1 to 4 & Good Relationship with Supervisors \\
\hline Q50za & $\begin{array}{l}\text { My supervisor tries to make my job as interesting as } \\
\text { possible }\end{array}$ & 1 to 4 & Good Relationship with Supervisors \\
\hline
\end{tabular}

We combine items Q50t, Q50u, Q50v, and Q50w into the single index "Good Relationship with Coworkers”; and items Q50x, Q50y, Q50z, and Q50za into the single index "Good Relationship with Supervisors". In doing so, we average the scores across the items included in the index and set the final index to missing if more than half of the items have missing values.

All questions about job characteristics are only asked of those respondents who are working for pay at the time of the interview. Since we select full-time employees in wave $t$ and focus on their employment transitions from wave $t$ to wave $t+1$, we use individual job characteristics observed in wave $t$ when all individuals in the selected sample are in full-time employment. 


\section{A.3 Personality traits}

The items below are taken from the HRS leave behind questionnaire. These questions are asked in waves 8, 9, and 10 (2006, 2008, and 2010). All items ask "Please indicate how well each of the following describes you" using the scale $1=$ a lot; 2 = some; 3 = a little; $4=$ not at all.

\begin{tabular}{|c|c|c|c|}
\hline Variable & Question & Code & Big Five Assignment \\
\hline Q33a & Outgoing & 1 to 4 & Extraversion \\
\hline Q33b & Helpful & 1 to 4 & Agreeableness \\
\hline Q33c & Moody & 1 to 4 & Neuroticism \\
\hline Q33d & Organized & 1 to 4 & Conscientiousness \\
\hline Q33e & Friendly & 1 to 4 & Extraversion \\
\hline Q33f & Warm & 1 to 4 & Agreeableness \\
\hline Q33g & Worrying & 1 to 4 & Neuroticism \\
\hline Q33h & Responsible & 1 to 4 & Conscientiousness \\
\hline Q33i & Lively & 1 to 4 & Extraversion \\
\hline Q33j & Caring & 1 to 4 & Agreeableness \\
\hline Q33k & Nervous & 1 to 4 & Neuroticism \\
\hline Q33l & Creative & 1 to 4 & Openness to Experience \\
\hline Q33m & Hardworking & 1 to 4 & Conscientiousness \\
\hline Q33n & Imaginative & 1 to 4 & Openness to Experience \\
\hline Q33o & Softhearted & 1 to 4 & Agreeableness \\
\hline Q33p & Calm & 1 to 4 & Neuroticism \\
\hline Q33q & Intelligent & 1 to 4 & Openness to Experience \\
\hline Q33r & Curious & 1 to 4 & Openness to Experience \\
\hline Q33s & Active & 1 to 4 & Extraversion \\
\hline Q33t & Careless & 1 to 4 & Conscientiousness \\
\hline Q33u & Broad-minded & 1 to 4 & Openness to Experience \\
\hline Q33v & Sympathetic & 1 to 4 & Agreeableness \\
\hline Q33w & Talkative & 1 to 4 & Extraversion \\
\hline Q33x & Sophisticated & 1 to 4 & Openness to Experience \\
\hline Q33y & Adventurous & 1 to 4 & Openness to Experience \\
\hline Q33z & Thorough & 1 to 4 & Conscientiousness \\
\hline
\end{tabular}

We follow Duckworth and Weir (2010) and measure the Big Five personality traits according to the assignment shown in this table. We reverse the scale of all original question items so that 1 is "not at all" and 4 is "a lot", except for items Q33p (Calm) and Q33t (Careless), which use the original scale. When creating the five indexes corresponding to the Big Five personality traits we average the scores across the items included in the index and set the final index to missing if more than half of the items have missing values. In order to maximize the sample size for our analysis, we assume that personality traits are stable over time and assign to each individual the average of their available personality measures over the observation period. 